\title{
Non-synchronous trading and testing for market integration in Central European emerging markets
}

Citation for published version (APA):

Schotman, P. C., \& Zalewska, A. (2006). Non-synchronous trading and testing for market integration in Central European emerging markets. Journal of Empirical Finance, 13, 462-494.

https://doi.org/10.1016/j.jempfin.2006.04.002

Document status and date:

Published: 01/01/2006

DOI:

10.1016/j.jempfin.2006.04.002

Document Version:

Publisher's PDF, also known as Version of record

Document license:

Taverne

Please check the document version of this publication:

- A submitted manuscript is the version of the article upon submission and before peer-review. There can be important differences between the submitted version and the official published version of record.

People interested in the research are advised to contact the author for the final version of the publication, or visit the DOI to the publisher's website.

- The final author version and the galley proof are versions of the publication after peer review.

- The final published version features the final layout of the paper including the volume, issue and page numbers.

Link to publication

\footnotetext{
General rights rights.

- You may freely distribute the URL identifying the publication in the public portal. please follow below link for the End User Agreement:

www.umlib.nl/taverne-license

Take down policy

If you believe that this document breaches copyright please contact us at:

repository@maastrichtuniversity.nl

providing details and we will investigate your claim.
}

Copyright and moral rights for the publications made accessible in the public portal are retained by the authors and/or other copyright owners and it is a condition of accessing publications that users recognise and abide by the legal requirements associated with these

- Users may download and print one copy of any publication from the public portal for the purpose of private study or research.

- You may not further distribute the material or use it for any profit-making activity or commercial gain

If the publication is distributed under the terms of Article $25 \mathrm{fa}$ of the Dutch Copyright Act, indicated by the "Taverne" license above, 


\title{
Non-synchronous trading and testing for market integration in Central European emerging markets
}

\author{
Peter C. Schotman ${ }^{\mathrm{a}, \mathrm{b}}$, Anna Zalewska ${ }^{\mathrm{c}, \mathrm{d}, *}$ \\ a Limburg Institute of Financial Economics, Maastricht University, The Netherlands \\ ${ }^{\mathrm{b}} C E P R, U K$ \\ c School of Management, University of Bath, UK \\ ${ }^{\mathrm{d}}$ CMPO, University of Bristol, UK
}

Accepted 21 April 2006

Available online 30 June 2006

\begin{abstract}
The paper contributes to the literature on integration of stock markets by addressing the issue of nonsynchronous trading. We argue that controlling for time differences in trading hours of stock markets is important and show that time-adjustment improves estimates of market integration. We also show that using weekly frequency does not sidestep the consequences of the time-match problem but leads to significant loss of information. We show that the nature of integration of stock exchanges operating in the Czech Republic, Hungary, and Poland with the stock markets of Germany, UK and US in the period 1994-2004 is very dynamic. Finally, the study shows that the autocorrelation of returns on the main market indices of these emerging markets have declined over time.
\end{abstract}

(C) 2006 Elsevier B.V. All rights reserved.

JEL classification: G14; G15

Keywords: Market integration; Market efficiency; Non-synchronous trading; Emerging markets; Kalman filter

\section{Introduction}

Documenting changes in integration of the emerging stock markets of Central and Eastern Europe (CEE) has been hampered for many years by data problems stemming, in particular, from the limited sample periods and the poor quality of available information (e.g., unreliable, incomparable, and incomplete statistics). Since the CEE stock markets now play a far more

\footnotetext{
* Corresponding author. School of Management, University of Bath, Bath BA2 7AY, UK. Tel.: +44 1225 384354; fax: +44 1225386861 .

E-mail address: a.zalewska@bath.ac.uk (A. Zalewska).
} 
important role in the international financial environment and the contribution of these markets to internationally diversified portfolios has grown substantially, it is crucial to understand the relationship between them and developed markets. Using carefully aligned daily data we analyse comovements between returns on three CEE main stock market indices (i.e., indices of the Czech Republic, Hungary, and Poland) and returns on the main indices of three developed stock markets (i.e., of Germany, UK and US) in the period 1994-2004. We find that the comovements change over time, with the Asian and Russian Crisis being strongly pronounced. There is also some evidence that the burst of the e-commerce bubble affected the comovement of the markets. This suggests that these CEE markets display great sensitivity to external shocks.

We emphasize alignment of non-synchronous data recorded on different stock markets. Time mismatch arises when stock market returns used in regressions are recorded on different exchanges at different times. The problem is common in studies of market integration and contagion, and is generally dealt with by either lowering the data frequency (weekly or monthly data instead of daily), using leads and lags, or using rolling multiday returns. These methods, however, are not suitable when returns are autocorrelated or when one of the research objectives is to test for the market predictability. Furthermore, higher frequency data allows for more precise estimation of variances and covariances.

The conventional view is that there is a choice between daily data with potential time-matching problems and weekly or monthly data, which sidesteps the problem but at the expense of losing information. We document that the effects of time matching are significant for both daily and weekly returns. With daily data, precise handling of the time-mismatch problem is necessary to avoid misinterpretation of the evidence. Even on a weekly basis, however, time-matched regressions show a stronger relation between CEE and developed markets than non-time-matched regressions. Thus, using weekly frequency does not completely sidestep the consequences of the time-mismatch problem, whereas the loss of information when moving from daily to weekly data is high.

The benefits of daily data are most clearly visible around two important, but separate, shocks that occurred soon after one another: the Asian Crisis of 1997 and the Russian Crisis of 1998. With daily data these two events stand out as two separate instances when the integration with the developed markets sharply increased. ${ }^{1}$

Our results contribute to the existing literature in several ways. First, using daily data we contribute to the literature on the integration of emerging markets of Central and Eastern Europe (CEE). Since most of these markets started to operate in the mid-1990s, the short sample period and the data problems mean that there are very few studies on these markets. However, proper assessment of the CEE markets properties and, in particular, their integration with developed markets is vital given their growing economic significance and position within the EU. Recent studies, e.g., Pajuste et al. (2000) and Mateus (2004), argue that the CEE markets are highly segmented and that returns have an important predictable component. These conclusions are drawn from monthly observations. Using time-aligned daily data we identify the dynamic nature of the processes taking place on the CEE markets in the period 1994-2004, and in particular, a declining character of autocorrelation and high responsiveness to external shocks (e.g., the Asian and the Russian Crises). This may explain why the more traditional approach of testing for integration based on monthly observations and long-term linear relationships fails to provide statistically significant results. Our time-matched results also contradict those of Rockinger and Urga (2001), who were unable to find statistically significant results based on non-matched daily observations.

\footnotetext{
1 As it is explained in Section 2, following Bekaert and Harvey's (2002) conclusions, we use the word "integration" in a broader sense, meaning comovements of markets. That is, we go beyond a classical concept of asset pricing relations.
} 
Second, our study of the time-varying pattern of market comovements contributes to the discussion of the effects and aftermath of the Asian and the Russian Crises on international markets. These two crises led to a dramatic increase in the correlations between most countries in the world. Forbes and Rigobon (2002) argue that these higher correlations are due to an increase in volatility in world markets because of the crisis. Following this reasoning the cross-country correlations should decline as soon as the volatility of international markets returned to its "natural" level. We find that the impact of the crises was short-lived, but the covariance between the returns on the CEE's and the developed stock markets' indices increased far more dramatically than what might be explained by an increase in the world volatility. In addition, we find substantial differences in responses of the CEE markets to the crises with the Hungarian market being most and the Czech market being least sensitive. This finding is consistent with Boyer et al. (2006) who document that "stock market crises are spread globally through asset holdings of international investors". Among the three emerging markets discussed in this paper the Hungarian market had the highest foreign share ownership level and the Czech market lowest.

Third, we contribute to the literature on the links between geographical distance and market integration. The regression coefficients estimated for the European developed exchanges and the US market when compared with the CEE markets exhibit a similar cyclical pattern once the correction for differences in trading hours between markets is in place. Without the time alignment, i.e., when same calendar day returns are used, the CEE markets seem less integrated with the US market than with the developed EU markets. This finding contrasts the view that geographical distance and market integration are negatively correlated (see e.g., Braker et al., 1999; Pretorius, 2002; Serra, 2000).

Although not central to the paper we also address the issue of currency denomination. In particular, we use exchange rates as a separate factor. Typically all returns are expressed in US dollars. However, when returns that are recorded on different, non-dollar, denominated markets are converted into dollars, a common factor is introduced. For instance, in regressions of the CEE stock markets' returns on the German stock market returns the dollar denomination creates a common factor when the exchange rates of Germany and the local CEE currencies against the US dollar are positively correlated. This is an important issue since two of the emerging markets used in our studies have tied their currencies to the German Mark, and later all three tied their currencies to the Euro. Within an international asset pricing model Adler and Dumas (1983) have shown that the currency denomination of returns matters if relative Purchasing Power Parity does not hold. Without PPP real exchange rates are a risk factor.

The rest of the paper is organised as follows. Section 2 provides a brief introduction to the issues of testing for market integration and non-synchronous trading. Section 3 introduces the emerging markets that are the core of our study. Section 4 discusses the models that are used in the empirical part of the paper. Section 5 presents the data, discusses its properties and the strategy of data matching. The main findings can be found in Section 6. Section 7 closes with conclusions.

\section{Related literature}

Stock markets are called integrated when assets with identical risk characteristics have the same expected return. ${ }^{2}$ Various asset pricing model specifications, based on single- or multifactor CAPM, are employed to define the appropriate risk characteristics. Multi-factor models use various macroeconomic variables of national and foreign origin to test whether emerging market

\footnotetext{
${ }^{2}$ See, for example, Bekaert and Harvey's $(2002,2003)$ extensive surveys of the emerging markets literature.
} 
returns can be explained by domestic and/or global factors. In particular, changes in the behaviour of emerging market stock returns are related to changes in the macroeconomic environment. Such tests, due to the frequency of macroeconomic variables, can be conducted on monthly observations at best (see e.g., Bekaert and Harvey, 1995, 1997).

Bekaert and Harvey (2002) evaluate stylised characteristics of Latin American, Asian and African emerging markets and of their integration with developed markets. First, they conclude that the CAPM beta coefficient of an emerging stock market with respect to the global stock market index does not explain expected returns. The strong theoretical assumptions of the (International) CAPM are often not fulfilled for emerging markets. As a consequence Bekaert and Harvey (2002) use more complex multi-factor models and focus on the time variation of the explanatory power of independent variables that are chosen to control for local and global factors. Second, emerging markets appear to be less efficient than developed markets. In particular, emerging markets' equity returns are characterised by higher serial correlation than equity returns on developed markets. This is one of the reasons why asset pricing implications of both unconditional and conditional models are easily rejected.

Third, the explanatory power of various macroeconomic variables (i.e., integration) varies over time. The time changes are mostly gradual, but sometimes the response to some events (e.g., political) can be dramatic. Correlation between markets tends to increase temporarily in periods of high world market volatility. ${ }^{3}$ Bekaert and Harvey (2002) note that although changes in the correlations, or regression coefficients, are not a theoretical requirement of integration, they are a strong indicator of it.

The Bekaert and Harvey $(2002,2003)$ surveys do not cover Central and Eastern Europe. For years research on CEE markets has been hampered by problems with data. Recently several studies have been conducted on monthly data. Both Pajuste et al. (2000) and Mateus (2004) find that the CEE markets are highly segmented and that returns have an important predictable component. Pajuste et al. (2000) use 50 monthly observations between June 1994 and July 1998 to identify the risk factors of CEE stock returns. One-year rolling correlations between CEE and German stock returns show large swings in this 4-year period. Standard errors, although not reported, for these monthly data must be huge. ${ }^{4}$ Pajuste et al. (2000) find that returns are mostly related to other emerging markets and to measures of sovereign risk, and less to returns in developed markets. Correlations with the German market jump upward, however, in the last year of their sample. Moreover, the lagged instruments have a strong predictive power over the whole period in question.

Mateus' (2004) analysis of predictability of stock markets of the EU accession countries uses monthly observations in the period 1997-2002. He confirms problems with standard global asset pricing models as the tool for modelling emerging markets return predictability and finds that lagged instruments have predictive power for CEE excess stock returns. Furthermore, he also confirms that correlation of these markets with developed markets varies over time and increases in the period 1998-2002. This increase is interpreted as a result of the Russian Crisis.

\footnotetext{
${ }^{3}$ Forbes and Rigobon (2002) argue that an increase in correlation during periods of financial distress does not indicate temporal increase in integration or contagion. They show that correlations increase by construction when the world variance increases, while betas of all countries with respect to the world market remain constant.

${ }^{4}$ A crude estimate of the standard error of a correlation is $1 / \sqrt{ } T$. The standard error on the difference between the correlations in two samples is $\sqrt{ } 2 / T$. For 1 -year correlations $(T=12)$ the difference between the correlations in two different years must thus be at least $2 / \sqrt{ } 6=0.82$ to be significant. True standard errors are likely to be much higher due to autocorrelations in returns.
} 
In summary, studies on the integration of emerging market agree that asset pricing models have low explanatory power. Therefore, following Bekaert and Harvey (2002) and Bekaert et al. (2005) we concentrate on an investigation of time-paths of market comovements and the explanatory power of the models as indicators of integration. However, this obliges us to use higher frequency data. In contrast to estimates of realised average returns that do not depend on frequency but mostly on the length of a sample period, the estimates of variances and covariances greatly benefit from higher frequency data. ${ }^{5}$ Daily, as opposed to monthly data improve the estimates of risk characteristics.

In this respect our study is closely related to Rockinger and Urga (2001) who to deal with the data problems on CEE markets abandon the monthly data frequency and the use of macroeconomic variables. They employ 3 years of daily returns (April 1994 to July 1997) for Poland, Hungary, Czech Republic and Russia and pair them with returns on the UK, US and German stock market indices to estimate changes in integration and predictability. They find that stock markets of the four post-communist countries appear unrelated to the stock markets of the US and the UK and do not show a tendency for increased integration over time. Even the relation with Germany, the geographically closest market, is weak. For instance, by the end of their sample the $95 \%$ confidence interval of the beta estimated for Poland with respect to the German stock market has fallen to $(-0.2,0.2){ }^{6}$

Martens and Poon (2001) note that correlations based on daily data substantially underestimate the true correlations if data are not well-aligned. They show that the unconditional correlation between the US S\&P500 and the UK FTSE100 increases from 0.37 to 0.63 if they move from returns based on closing prices to synchronous returns based on prices recorded at 16:00 GMT. We confirm their findings. Taking care of the alignment of the daily data of the CEE countries increases the size and significance of the estimated coefficients and the explanatory power of our model specifications. In consequence, our estimates of market integration are much higher than those of Rockinger and Urga (2001).

Constructing synchronous returns for the CEE markets is, however, more complicated than for the developed markets studied by Martens and Poon (2001). The opening times of CEE stock markets varied substantially in the period 1994-2004 (e.g., the timing of trading sessions on the Budapest Stock Exchange has been modified six times) and were always shorter than trading sessions of the developed markets selected for the study. Furthermore, closing values of the emerging market indices were determined much earlier than the closing values of the developed markets' indices, and sometimes even before the opening values of the developed markets' indices were known. We resolve the problem of data misalignment by matching daily returns of a developed market as closely as possible with the closing returns of the CEE markets. To do so intraday observations of the developed market indices are used.

Problems with non-synchronous trading are well discussed in the financial literature. The Scholes and Williams (1977) correction of using leads and lags of the independent variable (in our case of the developed market returns) is the frequently applied solution. However, the application of the Scholes-Williams type of correction to emerging markets has an unfortunate side effect. The existence of the leads and lags of the developed market returns in the regression model specification when an emerging market's returns are autocorrelated can interfere with predictability as an indicator of market inefficiency. Predictability of an emerging market may

\footnotetext{
5 This point has been made most forcibly in the literature on realised volatility. See for example Andersen et al. (2001, 2003).

${ }^{6}$ See Table 2 and Figs. 2-4 in Rockinger and Urga (2001).
} 
pick up some of the non-synchronous trading effect due to the misalignment of the daily returns of emerging and developed markets but may also be a signal of market inefficiency. Overlapping multiday returns as in Forbes and Rigobon (2002) are an alternative way of dealing with nonsynchronous trading. ${ }^{7}$ Again, this approach interferes with studies on the size and significance of autocorrelation. Hamao et al. (1990) address the non-synchronicity of international stock markets by disaggregating returns into open-to-close and close-to-open returns. This allows them to study how innovations to the US market index during trading hours in New York spreads to Japanese returns during the Tokyo trading hours. Since open-to-close and close-to-open returns have very different time series properties, the further disaggregation leads to additional modelling complexities when applied to measuring the comovements between emerging and developed markets. It also does not solve the misalignment problem for the relation between CEE markets and the markets of Germany and of the UK, which have largely overlapping trading hours. Finally, Martens and Poon (2001) note that model based corrections are sensitive to model specification. This further motivated us to adopt direct time-adjustment of the data instead of model based corrections.

\section{Emerging markets of Central and Eastern Europe}

The creation of private ownership via privatisation of state-owned enterprises, preparation of the ground for the market of government and corporate debt, and creation of corporate control instruments were among the main objectives of the reformers in the post-communist countries when designing local stock markets. The different solutions that have been implemented indicate that, although the notion of an efficient market is theoretically well developed, the practical implementation of the idea is more cumbersome. ${ }^{8}$

As a result of the radically different approaches to privatisation and sequencing of the creation of the legal and operational base of a stock exchange, the CEE stock markets had dramatically different histories of development. For instance, as the result of gradual privatisation and the strong preference for foreign ownership, the Budapest Stock Exchange's (BSE's) growth has been very slow. The first trading session took place on 21 June 1990, but the shares of one company only (Ibusz Rt.) were under offer. By the end of the year six companies were listed with a total capitalisation of US\$0.26bn. A market index was not even calculated during these first months. The market index BUX was introduced on 2 January 1991, and lost about $16 \%$ of its value during the first 12 months. The first few years of market operation were rather cumbersome. Although gradually more and more companies were admitted for trading, investors did not seem attracted to them. Thin trading was a severe problem. For instant, although 23 companies were listed by the end of 1992 , the average daily number of transactions was just 27 , and in 1994, when our sample starts, on average, 229 transactions per day were recorded for 40 listed companies. ${ }^{9}$

Although the next few years brought rather slow growth in the number of listings and market capitalisation, liquidity of trade improved substantially. The BSE was at its peak in 1999 with 66 listed companies and total capitalisation of US\$16.4bn or $36.6 \%$ of GDP. At the same time the

\footnotetext{
${ }^{7}$ Aiit-Sahalia et al. (2005) analyse the econometrics of using overlapping returns in the context of high-frequency intraday data.

${ }^{8}$ Even in developed countries the issue of the optimal way of privatisation is widely debated. For example, see Grout et al. (2004), and Grout and Zalewska (2005) for a discussion on the undervaluation problem.

${ }^{9}$ Figures quoted after Annual Reports published by the Budapest Stock Exchange.
} 
Table 1

Main statistics of the Budapest, the Prague and the Warsaw Stock Exchanges

\begin{tabular}{|c|c|c|c|c|c|c|c|c|c|}
\hline & 1995 & 1996 & 1997 & 1998 & 1999 & 2000 & 2001 & 2002 & 2003 \\
\hline \multicolumn{10}{|c|}{ Budapest Stock Exchange } \\
\hline Shares & 42 & 45 & 49 & 55 & 66 & 60 & 56 & 49 & 53 \\
\hline \multicolumn{10}{|c|}{ MCap bn } \\
\hline Huf & 327.8 & 852.5 & 3058.4 & 3020.1 & 4144.9 & 3393.9 & 2848.8 & 2947.2 & 3469.9 \\
\hline US\$ & 2.3 & 5.2 & 15.0 & 13.8 & 16.4 & 11.9 & 10.2 & 13.1 & 16.7 \\
\hline$\%$ GDP & 5.99 & 12.89 & 36.64 & 29.90 & 36.05 & 28.25 & 19.38 & 19.47 & 18.7 \\
\hline \multicolumn{10}{|c|}{ Prague Stock Exchange } \\
\hline Shares & 1716 & 1670 & 320 & 304 & 195 & 151 & 102 & 79 & 65 \\
\hline \multicolumn{10}{|c|}{ MCap bn } \\
\hline $\mathrm{CzK}$ & 478.6 & 539.2 & 495.7 & 416.2 & 479.6 & 442.9 & 340.3 & 478.0 & 644.5 \\
\hline US\$ & 24.5 & 19.3 & 14.4 & 13.9 & 13.3 & 11.7 & 9.4 & 15.8 & 24.8 \\
\hline$\%$ GDP & 47.0 & 34.4 & 27.8 & 18.4 & 20.8 & 19.2 & 14.3 & 19.8 & 17.9 \\
\hline \multicolumn{10}{|c|}{ Warsaw Stock Exchange } \\
\hline Shares & 65 & 83 & 143 & 198 & 221 & 225 & 230 & 216 & 203 \\
\hline \multicolumn{10}{|c|}{ MCap bn } \\
\hline $\mathrm{Plz}$ & 11,271 & 24,000 & 43,766 & 72,442 & 123,411 & 130,085 & 103,370 & 110,565 & 167,717 \\
\hline US\$ & 4.29 & 8.05 & 10.79 & 20.08 & 29.8 & 31.4 & 35.5 & 40.5 & 44.8 \\
\hline$\%$ GDP & 3.4 & 5.8 & 9.3 & 13.0 & 19.9 & 18.1 & 13.7 & 14.3 & 17.3 \\
\hline
\end{tabular}

average daily number of transactions grew to $5846 .{ }^{10}$ However, although in 2000 there was not a strong correction (compared to that observed on many developed markets) the after 2000 figures indicate a mild decline in many statistics of the exchange. By the end of 2003 there were just 53 equity listings with the total capitalisation of US\$16.7 or about $20 \%$ of GDP. The number of transactions also dropped to 2788 per session. A dramatic increase in listings and capitalisation is not expected in the coming years. The privatisation of state-owned enterprises is nearly complete and for private issuances nearby exchanges in Austria and Germany may be more attractive than the thin domestic market. More annual statistics can be found in Table 1.

The Warsaw Stock Exchange (WSE) has also grown slowly. The first trading session took place on 16 April 1991. Shares of five newly privatised companies (Exbud, Krosno, Próchnik, Slaska Fabryka Kabli and Tonsil) were under offer. By the end of the calendar year nine stocks were listed with capitalisation of US\$ 0.15 bn (less than $0.2 \%$ of GDP). In contrast to the BSE, the WSE traded actively. Although only nine companies were traded by the end of 1991, the average number of transactions per session for that year was 877. By the end of 1994, 36 companies were listed, and the average daily number of transactions for that year was already 24,594 . However, 1994 was the last year of such a high level of trading. The market cooled down after the corrections that followed the introduction of Bank Slaski shares for trading. Unrealistically high expectations on the part of investors about the value of the Bank Slaski shares triggered the end of a "bubble" and led to a decline in the value of nearly all companies listed on the market. In the following years, i.e., when our analysis takes place, the number of listed equities increased, but the number of trades decreased substantially. By the end of 2003 there were 223 equity listings

\footnotetext{
10 The highest average number of transactions per session was recorded in 2000. It was 6424 .
} 


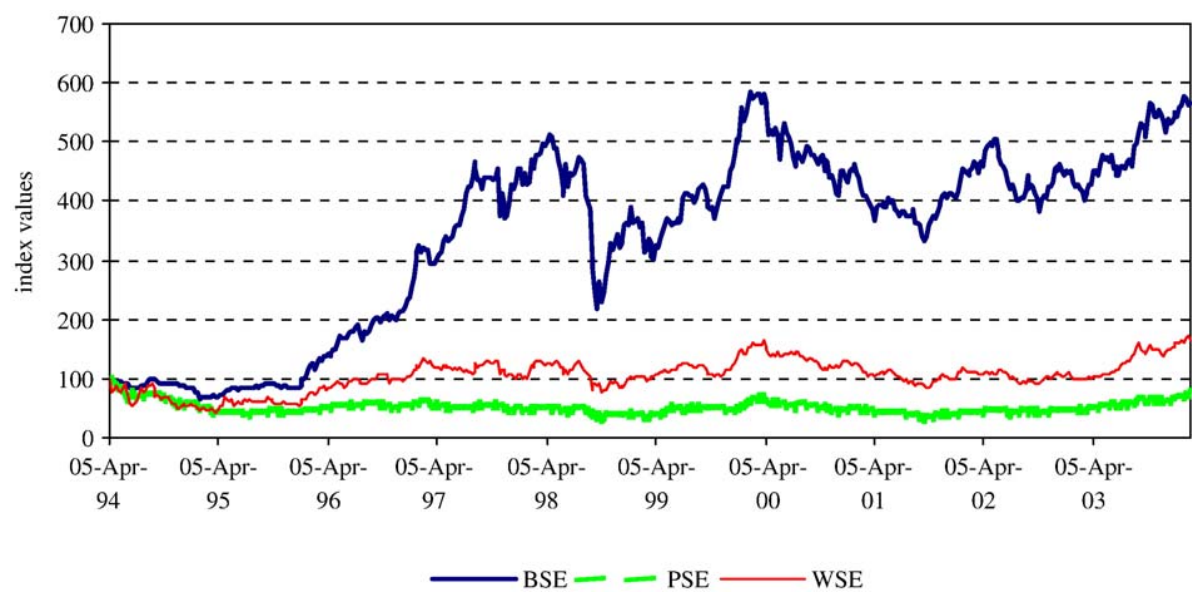

Fig. 1. Performance of the main indices calculated on the Budapest, the Prague and the Warsaw Stock Exchanges in the period April 1994-February 2004 (weekly observations).

with total capitalisation of US $\$ 44.8 \mathrm{bn}$ or $13 \%$ of GDP and the number of transactions per session was 12,228 .

The pattern of development of the Prague Stock Exchange (PSE) was the reverse to that of the BSE and the WSE. Although shares of only seven companies were offered during the first trading session on 6 April 1993, the mass privatisation pushed nearly 1000 stocks on the floor of the newly created exchange within the next 2 months. The PX50 market index was introduced on 7 April 1994. By the end of 1995 there were 1716 share listings with the total value of US $\$ 24.5 \mathrm{bn}$ or $47 \%$ of GDP. By the end of 2003 the PSE shrank to 65 equity listings of the total capitalisation of US\$25bn (27\% of GDP). ${ }^{11}$ The dramatic decline in the number of listed shares was a side effect of the mass privatisation programme implemented in the early and mid-1990s. Local authorities' expectations of the role that local banks and newly created investment funds would play in the corporate restructuring of the privatised companies were far too optimistic and as a result prudent behaviour and use of tight budget constraints were not common practice. The consequence was a massive collapse of privatised companies, the need to bailout banks and a subsequent withdrawal of many listings from the PSE in 1997. When in 1997 the Asian Crisis was shaking many international markets, the Czech economy was struggling against its own, domestically generated, financial distress.

Fig. 1 presents time-paths of the main CEE stock market indices in the period April 1994February 2004. For comparison purposes the initial values of the indices are normalised to 100. While the history of returns for the three markets is very different, the general trends across the three markets exhibit similarities, especially since 1998. For instance, the markets' indices were on an upward trend from 1999 until April 2000, they subsequently declined and started to grow again in 2002. However, it seems, that although the three exchanges were shaken by the Russian Crisis of 1998, it was the BUX index of the BSE that was most affected. In contrast, the Asian Crisis of 1997 is clearly visible on the BSE and the WSE, but not on the PSE. This may be consistent with the fact that in 1997 the Czech economy was driven by its own domestic trouble and hence not showing much sensitivity to external factors. Boyer et al.'s (2006) result that

${ }^{11}$ In June 2004 there are 61 shares of $€ 24.282 \mathrm{bn}$ (US\$29.242bn) listed on the PSE. 
international investors are responsible (at least in part) for spreading stock market crises is consistent with our finding that among the three CEE markets discussed in this paper, the BSE displays the highest level and the PSE the lowest level of sensitivity to the Asian and the Russian Crises. According to the stock market openness classification presented by Boyer et al. (2006) only $37.7 \%$ of total market capitalisation on the PSE was accessible to foreign investors in 1997. The corresponding statistics for the Hungarian and the Polish markets were $99.5 \%$ and $100 \%$ respectively. In practice, however, the proportions of foreign share ownership were much in favour of the BSE. The National Statistical Office of Hungary reports that $68.3 \%$ of the total equity value was in foreign hands in 1997. At the same time the foreign ownership of shares listed on the Polish exchange was below $20 \%{ }^{12}$

In the light of the above statistics, the natural question arises of whether the markets are efficient and integrated with the developed markets and what the time pattern of the evolution looks like. Although there is no theory that predicts how and when markets become efficient, a common belief suggests that emerging markets may display a high level of predictability at the early stages of market development. When markets become more settled, in the sense of establishing regulatory structures, trading systems, protection of minority shareholders, information disclosure, etc., and when markets participants become more experienced, the initial predictability (if any) diminishes. The early studies of market efficiency by Zalewska-Mitura and Hall (1999, 2000) document substantial changes in predictability of the WSE and the BSE in the first half of the 1990s.

As is the case with efficiency, there is no theory that explains how quickly the integration of emerging markets should occur. However, it is natural to expect that market integration is positively correlated with market stabilisation and an increase in economic openness of the country. Therefore, integration is to some extent a function of time, provided economic openness and stabilisation are not altered by shocks (e.g., political instability).

What form the time-path of development of the CEE markets takes is an important question for several reasons. The CEE markets have several common characteristics (e.g., they operate in countries that have been undergoing intensive economic reforms, they have a similar geographical location, similar time of creation, etc.) although they differ in operational fundamentals (e.g., different organisation of trade, admission of stocks to the exchange, etc.). ${ }^{13}$ These similarities and differences help to distinguish between individual and universal characteristics of exchanges. Finally, the countries in which the investigated exchanges operate became members of the EU in May 2004. Therefore, understanding their fundamental properties is of vital importance for the sustainable growth of the "old" EU members.

\section{Model specification}

Our methodology follows Rockinger and Urga (2001), who present their model as a variant of the models of Bekaert and Harvey $(1995,1997)$. We consider the time-varying parameter regression model

$$
r_{\mathrm{E}, t}=\alpha_{t}+\beta_{t} r_{\mathrm{D}, t}+\gamma_{t} r_{\mathrm{E}, t-1}+e_{t}
$$

\footnotetext{
${ }^{12}$ Federation of European Securities Exchanges reports that in 1999 the foreign share ownership reached 28.9\%. The pre-1999 statistics are not available, but since foreign investors were slow in entering the WSE, the 1997 statistics must be much lower than those of 1999 .

${ }^{13}$ For instance, the BSE was always a market with continuous trading, whereas initially the WSE and the PSE were markets with call trading.
} 
where $r_{\mathrm{E}}$ is the emerging market return, $r_{\mathrm{D}}$ is the return in a developed market, and $\alpha_{t}, \beta_{t}$, and $\gamma_{t}$ are time-varying parameters. The errors $e_{t}$, or idiosyncratic noise relative to the developed market, have a time-varying variance $\sigma_{t}^{2}$. The trend in expected returns is represented by $\alpha_{t}$, the predictability is measured by $\gamma_{t}$ provided $r_{\mathrm{D}, t}$ and $r_{\mathrm{E}, t-1}$ are orthogonal. We refer to $\beta_{t}$ as the "impact" coefficient.

Eq. (1) is not an asset pricing model. To interpret (1) as a form of the International CAPM, the factor $r_{\mathrm{D}}$ should represent the return on the world market portfolio, $\gamma_{t}$ should be zero, and $\alpha_{t}=\left(1-\beta_{t}\right) r_{\mathrm{f} t}$, where $r_{\mathrm{f}}$ is the risk-free rate of return. We therefore do not evaluate integration by the significance and size of $\alpha_{t}$. We instead focus on the covariance measures $\beta_{t}, \gamma_{t}$, and the total variation of the emerging market returns that can be explained by the returns on the developed market. We interpret a high value of $\beta_{t}$ as an indicator of market integration. If it is true that inefficiency decreases, but integration increases over time we should observe that the coefficients $\beta_{t}$ and $\gamma_{t}$ move in opposite directions, i.e., the autocorrelation coefficient $\gamma_{t}$ declines and the impact coefficient $\beta_{t}$ increases over time.

Another indicator of integration is the correlation between the emerging market and the developed market. The usual measure of correlation is the regression's $R^{2}$. Unfortunately, the regression's $R^{2}$ is less informative in the present case due to the time-varying nature of the regression parameters and the potential autocorrelation of the emerging market returns. The measure we report is closely related to the variance ratio developed by Bekaert and Harvey (1997). We compute the conditional variance of $r_{\mathrm{E}, t}$ given the regression parameters $\left(\alpha_{t}, \beta_{t}\right.$, and $\gamma_{t}$, and $\left.\sigma_{t}^{2}\right)$ and the conditional variance $\omega_{t}^{2}$ of the developed market returns $r_{\mathrm{D}}$. We denote the conditional variance of the emerging market returns by $\psi_{t}^{2}$. We assume that $r_{\mathrm{D}, t}$ is exogenous to $r_{\mathrm{E}, t}$, and therefore uncorrelated with $r_{\mathrm{E}, t-1}$. Taking the variance of both sides of (1), conditional on the parameters, gives

$$
\psi_{t}^{2}=\beta_{t}^{2} \omega_{t}^{2}+\gamma_{t}^{2} \psi_{t-1}^{2}+\sigma_{t}^{2}
$$

By recursive substitution, and under assumption of $\psi_{0}^{2}=0$, Eq. (2) can be rewritten as

$$
\psi_{t}^{2}=A_{t}^{2}+\sum_{j=0}^{t-1}\left(\prod_{i=0}^{j-1} \gamma_{t-i}^{2}\right) A_{t-j}^{2},
$$

with $A_{t}^{2}=\beta_{t}^{2} \omega_{t}^{2}+\sigma_{t}^{2}$. We divide both sides of (3) by $\psi_{t}^{2}$ and define the variance ratio

$$
\mathrm{VR}_{t}=\frac{\beta_{t}^{2} \omega_{t}^{2}}{\psi_{t}^{2}}+\frac{\sum_{j=1}^{t-1}\left(\prod_{i=0}^{j-1} \gamma_{t-i}^{2}\right) \beta_{t-j}^{2} \omega_{t-j}^{2}}{\psi_{t}^{2}} .
$$

The variance ratio, VR, is defined as the proportion of the variance in the emerging market returns that is attributed to the variance of the developed market. The first term is the squared correlation between the innovations of $r_{\mathrm{D}}$ and $r_{\mathrm{E}}$. This would be the $R^{2}$ in case of $\gamma_{t}=0$. The second term adds the further amount of variance of the emerging market related to the $r_{\mathrm{D}}$ coming indirectly through the lagged effects of $r_{\mathrm{E}, t-1}$. Since we expect $\gamma_{t}$ to be small, only the first few terms in the summation actually matter.

Various nonparametric techniques are available to estimate the parameters, using a moving window of observations around $t$ and a kernel to weight the observations. We use the parametric structure imposed by Rockinger and Urga (2001). Let $\theta_{t}$ be the vector containing $\alpha_{t}, \beta_{t}$, and $\gamma_{t}$. The parameter vector is assumed to follow the random walk process

$$
\theta_{t}=\theta_{t-1}+\eta_{t}
$$


where the innovations $\eta_{t}$ have zero mean and a diagonal covariance matrix $\Omega$. Even though the parameters are specified as a stochastic process, we treat the state Eq. (5) purely as a device to estimate the parameters at time $t$ using an optimal window of observations around $t$. The random walk specification implies a filter on the data in which parameters evolve smoothly and are mostly determined by the observations around time $t$. How much data around time $t$ is used for estimation of the coefficients depends on $\Omega$ and is estimated from the data. The specification is therefore well suited for depicting the likely evolution of emerging market integration and efficiency. ${ }^{14}$ Constant parameters are nested in (5) by the restriction $\Omega=0$, leading to $\theta_{t}=\theta_{0}$. We test this hypothesis using the likelihood ratio statistic.

To complete the model Rockinger and Urga (2001) specify asymmetric $\operatorname{GARCH}(1,1)$ processes for the conditional variances $\sigma_{t}^{2}$ and $\omega_{t}^{2}$. The conditional variances are required for the variance ratios in specification (4). Taking account of the heteroskedasticity of the errors also enhances the efficiency of the estimates of $\theta_{t}$. It effectively downplays very volatile periods of the emerging market. ${ }^{15}$ The model is designed for estimation with daily data. Since we are using daily data, we do not make a distinction between expected and unexpected returns $r_{\mathrm{D}}$ in the developed markets. On the daily frequency the variability of the conditional mean is negligible.

Apart from using a much longer sample of daily returns, we differ from Rockinger and Urga (2001) in various ways. Daily, or higher frequency, data lead to a number of subtle, but important, issues that stem from aligning $r_{\mathrm{E}}$ and $r_{\mathrm{D}}$. Emerging markets are often located in different time zones than developed markets, and have trading hours much shorter than the developed counterparts. In the case of the CEE markets the time-zone problem appears when the US data and, to some extent, the UK data are used. In addition, the issue of different opening hours arises very strongly. Opening hours of the emerging markets have varied substantially over the last decade. In the early years markets were open just for a few hours a day. The trading sessions thus hardly overlapped with the trading sessions of the developed markets. As a result of non-synchronous trading, closing prices of the developed markets contain a lot of news that could never have been incorporated in the closing prices of the emerging market for same calendar days. In the data section we describe how we align the returns for the developed markets with those of the emerging markets.

The use of daily data is also an important reason for taking a specific country return $r_{\mathrm{D}}$ instead of the global world market index in (1). Since different stock markets in the world are in different time zones and open during different hours, the construction of a daily global market return that is well-aligned with the opening hours of the CEE markets introduces even more non-synchronous trading problems. ${ }^{16}$

\footnotetext{
${ }^{14}$ Of course, the fact that the parameters follow a random walk is consistent with the possibility that they may be in part determined by some factors. For example, if the impact coefficient depends on foreign cash flows into the market, then the random walk specification is appropriate providing that foreign cash flows into the market are difficult to predict or are unpredictable. Although, there is no evidence on stochastic properties of daily foreign cash flows, what empirical evidence exists suggests that they are determined by external shocks (such as crises) that are themselves unpredictable (see, e.g., Boyer et al., 2006).

15 We estimated the model with various specifications of the GARCH process for $\sigma_{t}^{2}$, but this has hardly any effect on estimates of $\theta_{t}$.

${ }^{16}$ In theory it should be possible to construct a time-aligned world portfolio, but in practice it is not. Even in the case of developed markets we face difficulties as e.g., New Zealand's market closes for trading well before the American market opens. Emerging markets are even more cumbersome since for many of them there are no intraday observations (sometimes they are not recorded due to a call systems of transaction implementation). For similar reasons, since the developed markets used in the paper operate in different time zones, the problem of time-synchronisation means that we are unable to construct a well time-aligned portfolio for the developed markets.
} 
An important consideration is the currency denomination of the returns. In several research papers regressions based on (1) are run with $r_{\mathrm{E}}$ and $r_{\mathrm{D}}$ expressed in the same currency, which is usually the US dollar. Due to the alignment of the emerging market and developed market returns, it will also be necessary to align the exchange rates. ${ }^{17}$ Since we do not have sufficient intraday data on the exchange rates of the emerging market with respect to the US dollar, or any of the other developed market currencies, we have no choice but to work with local currency returns for both $r_{\mathrm{D}}$ and $r_{\mathrm{E}}$. Nevertheless currency effects are potentially important, so we add current and lagged exchange rate returns as explanatory variables.

Therefore, we run regression (1) with returns denominated in local currencies (instead of dollars) and with the relevant exchange rate returns as additional regressors:

$$
r_{\mathrm{E}, t}=\alpha_{t}+\beta_{t} r_{\mathrm{D}, t}+\gamma_{t} r_{\mathrm{E}, t-1}+\delta_{0 t} s_{t}+\delta_{1 t} s_{t-1}+e_{t},
$$

where $s_{t}$ is a daily change in the exchange rate, and the $\delta_{t}$ 's evolve as a random walk just as the other parameters. To address the issue of the time alignment the exchange rate change for the current day $t$ and the previous day $t-1$ are used in the equation specification. This is a second best option relative to the unavailable properly aligned exchange rate data.

Adding exchange rates as separate regressors is likely to reduce $\beta_{t}$. Consider the case of Poland as the emerging market and Germany as the developed market, and suppose both $r_{\mathrm{E}}$ and $r_{\mathrm{D}}$ are both measured in US dollars (the case considered by Rockinger and Urga, 2001). If the exchange rates of the Polish Zloty and German Mark (and later Euro) to the US dollar are positively correlated, part of the covariance between $r_{\mathrm{E}}$ and $r_{\mathrm{D}}$ is due to a common exchange rate component. Even if the two stock markets would be completely uncorrelated, they would still appear positively correlated picking up the exchange rate effect. ${ }^{18}$

To summarise, in the further part of the paper the following model specifications based on Eq. (1) are used:

Model 1: $r_{\mathrm{E}, t}=\alpha_{t}+\beta_{t} r_{\mathrm{D}, t}+e_{t}$; i.e., we do not control for autocorrelation

Model 2: $r_{\mathrm{E}, t}=\alpha_{t}+\beta_{t} r_{\mathrm{D}, t}+\gamma_{t} r_{\mathrm{E}, t-1}+e_{t}$; i.e., Eq. (1)

Model 3: $r_{\mathrm{E}, t}=\alpha_{t}+\beta_{t} r_{\mathrm{D}, t}+\gamma_{t} r_{\mathrm{E}, t-1}+\delta_{0, t} s_{t}+\delta_{1, t} s_{t-1}+e_{t}$, i.e., we additionally control for the exchange rate risk; i.e., Eq. (6).

In addition, each of these models uses three different specifications of the developed market returns. First, $r_{\mathrm{D}}$ is defined as a closing price return and regressed against the same calendar day return on the emerging market $r_{\mathrm{E}}$. Second, taking into account that it is only the previous day closing value of $r_{\mathrm{D}}$ that is known (if we restrict ourselves to using closing values) when the value of $r_{\mathrm{E}}$ is determined, we use a 1 day lag for the developed market return $\left(r_{\mathrm{D}, t-1}\right)$ to match it with $r_{\mathrm{E}, t}$. Finally, based on information on intermediate values of $r_{\mathrm{D}}$, we construct an index that matches as closely as possible the timing of closing values of the emerging market returns.

\footnotetext{
${ }^{17}$ For the purpose of this analysis the daily exchange rates provided by the corresponding national banks of the emerging markets are used. They are provided before the midday.

${ }^{18}$ Since we separate the exchange rates, we do not further investigate the issue of bias caused by the common exchange rate factor. However, to highlight the issue we would like to mention that the correlation of the daily changes of the Polish zloty to the US dollar and of the Euro to the US dollar exchange rates was as high as 0.87 at the beginning of the investigated period (1994-1996), and remains relatively high, 0.56, at the end of the period (2002-2004). Similar figures characterise the other markets analysed in this paper.
} 
All together we consider 81 model specifications: each of the three emerging markets (Hungary, Czech Republic and Poland) is regressed against three developed markets (Germany, UK and US) using three different definitions of returns (close-to-close on the same day, close-toclose on the previous day, and matched with the closing price of the emerging market) using three different models. To discriminate between the various models we use the Schwartz criterion. The Schwartz criterion performs consistent model selection based on likelihood values for non-nested models. Most of our further analysis will focus on graphs of the time-path of the betas for the time-matched, same day or previous day returns.

\section{Data}

Our data set consists of daily returns on three emerging market indices (BUX of the BSE, PX50 of the PSE, and WIG of the WSE), and on three indices of developed countries (DAX30 of the Frankfurt Stock Exchange, FTSE100 of the London Stock Exchange and S\&P500 of the New York Stock Exchange) over the period 7 April 1994-27 February 2004.

The US and the UK exchanges are chosen because they are biggest in the world. The German market has been chosen for two reasons. First, the German economy is one of most dominant within the EU. Second, German investment in the post-communist countries has been substantial, hence among the developed economies we would expect that the German market is most integrated with the CEE emerging markets.

Although the BSE and the WSE have been operating since 1990 and 1991 respectively, the starting date of 7 April 1994 is chosen to match the introduction of the PX50 index on the PSE. This allows us to cover the longest common period of market operation for the three emerging markets. At present all three markets operate in a continuous trading system. At the beginning of our sample, however, the WSE and the PSE operated in a call system (prices of stocks were evaluated once a day). The exact timings of the closing values determination of the market indices have changed several times during the last decade.

Table 2

Data summary

\begin{tabular}{|c|c|c|c|c|c|}
\hline Country & Stock market & Index & Currency & $\begin{array}{l}\text { Number of } \\
\text { observations }\end{array}$ & $\begin{array}{l}\text { Intraday } \\
\text { (GMT) }\end{array}$ \\
\hline \multicolumn{6}{|l|}{ Emerging markets } \\
\hline Czech Republic & $\begin{array}{l}\text { Prague Stock } \\
\text { Exchange }\end{array}$ & PX50 & Czech Koruna & 2403 & Closing value \\
\hline Hungary & $\begin{array}{l}\text { Budapest Stock } \\
\text { Exchange }\end{array}$ & BUX & Hungarian Forint & 2455 & Closing value \\
\hline Poland & $\begin{array}{l}\text { Warsaw Stock } \\
\text { Exchange }\end{array}$ & WIG & Polish Zloty & 2433 & Closing value \\
\hline \multicolumn{6}{|c|}{ Developed markets } \\
\hline Germany & $\begin{array}{l}\text { Frankfurt Stock } \\
\text { Exchange }\end{array}$ & DAX30 & Euro $(€)$ & 2491 & $\begin{array}{l}\text { Opening value, values at } \\
\text { 10:00, 12:00, 14:00, 16:00, } \\
\text { closing value }\end{array}$ \\
\hline UK & $\begin{array}{l}\text { London Stock } \\
\text { Exchange }\end{array}$ & FTSE100 & British Pound (£) & 2499 & $\begin{array}{l}\text { Opening value, values at } \\
\text { 10:00, 12:00,14:00,16:00, } \\
\text { closing value }\end{array}$ \\
\hline US & $\begin{array}{l}\text { New York Stock } \\
\text { Exchange }\end{array}$ & S\&P 500 & US dollar (\$) & 2492 & $\begin{array}{l}\text { Opening value, value at } \\
16: 00 \text {, closing value }\end{array}$ \\
\hline
\end{tabular}


Developed market indices are available at higher frequency over the whole period. ${ }^{19}$ Values of the S\&P500 index at three time points a day are available, i.e., index's opening and closing values (at 9:00 pm), as well as its value at 4:00 pm (note, time is always stated as GMT). The closing values of the UK and the German indices are recorded at 4:30 pm. There is also information about the value of the indices at 10:00 am, 12:00 pm, 2:00 pm and 4:00 pm, and their opening values. Although the exact timing of the opening prices is not known, it can be assumed that they correspond to the opening times of the trading sessions, i.e., the opening value of the FTSE100 and of the DAX are recorded at 8:00 am and of the S\&P500 is recorded at 2:30 pm. We feel that we can make this assumption, because the developed markets are liquid enough to guarantee that first transactions take place soon after the market opens. It should also be noted that when the opening values are used for the analysis (i.e., in the case of the S\&P500 index) the difference between the opening time of the developed market and the closing time of the emerging market is sufficient to secure that transactions took place. Table 2 offers data set summary.

\subsection{Day matching}

Comparing daily observations across markets is inevitably burdened with difficulties related to matching observations. Because markets trade on different days, for example, due to different national holidays, religious festivities, and other, often unexpected, events (e.g., the closure of the American exchanges after the September 11 terrorist attack), some adjustment of returns is necessary. In addition, at the early stages of their operation the exchanges did not trade 5 days per week. The WSE traded on Mondays, Tuesdays and Thursdays only until the end of June 1994. In the period July-September 1994 there were additional sessions on Wednesdays. Five sessions per week were introduced on 1 October 1994. The PSE introduced five sessions per week on 19 September 1994. Before then sessions were on Mondays, Tuesdays and Thursdays only. Such practices lead to different number of observations per country (see Table 2).

We tailor our time series to the needs of the dependent variable, i.e., an emerging market. That is, we remove all returns from the developed market index that do not have a corresponding value in the emerging market index. More precisely, if the emerging market is shut on day $t$, a corresponding return $\left(r_{\mathrm{D}, t}\right)$ from the developed market is removed when same day returns are used for regressions. However, if the emerging market trades on day $t$, but the developed market does not (there are only a few such cases), then we assume that there is no information coming from the developed market on that day and represent it by a zero return.

\subsection{Time matching}

The main difficulty stems from the different trading hours on the emerging and the developed markets. The differences are twofold. First, the emerging markets come from different time zones than the US and UK markets. Second, the emerging stock exchanges have much shorter trading sessions than the exchanges in developed markets. As a consequence, the recorded closing values of the emerging market indices do not fully correspond to the closing values of the developed market indices although formally they are denoted by the same day, say $t$. For instance, for several years the closing values of emerging markets indices were determined on times when the US market was not even open yet. Therefore, not only closing, but also opening values of the US market were not determined when the emerging market's

\footnotetext{
${ }^{19}$ We use DataStream as a source of all time series used in the regression analysis.
} 
index values were already fixed. In the light of this, dealing with the timing mismatch is of vital importance.

\subsection{1. $B U X$}

Trading hours of the BSE changed frequently in the period 1994-2004. Until the end of 1995 trading would end at noon. In the period January 1996-19 November 1998, it would finish at 12:15 pm, between 20 November 1998 and 17 January 1999 at 12:45 pm. In the period 18 January 1999-16 May 1999 the trading hours were extended for one more hour (i.e., until 1:45 pm). The trading hours until 4:00 pm were introduced from 17 May 1999 to 29 July 2001. Since 30 July 2001 trading finishes at 3:30 pm.

This means that over the whole period in question the closing values of the BUX index were determined well before the closing values of the European developed markets were set. The smallest difference in trading hours of the BSE and of the developed exchanges was between 1999 and 2001 (a half hour with the European exchanges and five and a half hour with the US exchange). Moreover, until May 1999 the BSE would stop trading even before the US market was open. This indicates that the comparison of the returns calculated for the same calendar days for the BSE and the developed markets, and the US market in particular, may lead to false conclusions.

To minimise the mismatch of the trading hours between the exchanges the intermediate values of the developed market indices are employed to construct time series that more closely corresponds to the timing of the BUX index. In particular, the time-adjusted S\&P500 time series is constructed of the previous calendar day closing values of the S\&P500 index until 16 May 1999, the values recorded at 16:00 in the period 17 May 1999-29 July 2001, and the opening values of the index for the same calendar day after 30 July 2001. The time-adjusted DAX30 and time-adjusted FTSE100 indices are constructed according to the rule: until 16 May 1999 the noon values of the indices are taken, in the period 17 May 1999-29 July 2001 the values recorded at 4:00 pm are taken, and finally, the values recorded at 2:00 pm are taken for the rest of the sample. This matching allows us to regress the returns of the BUX index on the returns of the developed markets' indices that are recorded as close in time as our information lets us, but before the trading on the BSE closes.

For the remainder of the paper the time series of returns recorded on the developed markets are referred to as the same day returns if they correspond to the same calendar day as the returns calculated on the BUX index. We talk about previous day returns if they denote returns lagged by 1 day according to the Hungarian returns, and time-adjusted returns if they are constructed according to the above described matching rule. The same notation is applied to the other two emerging markets safe for the fact that time adjustment rules differ depending on the timing of the emerging market. These rules are described below and summarised in Table 3 .

\subsection{2. $P X 50$}

Significant changes also took place in the trading system and consequently in trading hours on the PSE. In the early stages of the PSE's opening prices of transactions were determined within a call system. Prices based on orders submitted between 7:00 and 9:00 am were determined between 9:00 and 11:00 am, and finally announced at 11:00 am. Additional orders (at prices already fixed) were traded between 11:00 am-12:00 pm. ${ }^{20}$ On 15 March 1996 the

\footnotetext{
${ }^{20}$ We are very grateful to Eva Hoskovcova of the PSE Information Division for clarifying this point to us.
} 
Table 3

Summary of the time-matching procedure

\begin{tabular}{|c|c|c|c|}
\hline \multirow{2}{*}{$\begin{array}{l}\text { Timing of the developed } \\
\text { market indices }\end{array}$} & \multicolumn{3}{|l|}{ Emerging market indices } \\
\hline & PX50 & BUX & WIG \\
\hline \multicolumn{4}{|c|}{ DAX30 and FTSE100 indices } \\
\hline $10: 00$ value & 7 April 1994-14 March 1996 & & $\begin{array}{l}7 \text { April } 1994- \\
15 \text { November } 2000\end{array}$ \\
\hline $12: 00$ value & $\begin{array}{l}15 \text { March } 1996- \\
15 \text { March } 1998\end{array}$ & 7 April 1994-16 May 1999 & \\
\hline $14: 00$ value & $\begin{array}{l}16 \text { March } 1998- \\
27 \text { February } 2004\end{array}$ & $\begin{array}{l}30 \text { July } 2001- \\
27 \text { February } 2004\end{array}$ & $\begin{array}{l}16 \text { November } 2000- \\
27 \text { February } 2004\end{array}$ \\
\hline $16: 00$ value & & 17 May 1999-29 July 2001 & \\
\hline \multicolumn{4}{|l|}{$S \& P 500$} \\
\hline $\begin{array}{l}\text { Previous day } \\
\text { closing value }\end{array}$ & 7 April 1994-15 March 1998 & 7 April 1994-16 May 1999 & $\begin{array}{l}7 \text { April 1994- } \\
15 \text { November } 2000\end{array}$ \\
\hline Opening value & $\begin{array}{l}16 \text { March } 1998- \\
27 \text { February } 2004\end{array}$ & $\begin{array}{l}30 \text { July } 2001- \\
27 \text { February } 2004\end{array}$ & $\begin{array}{l}16 \text { November } 2000- \\
27 \text { February } 2004\end{array}$ \\
\hline $16: 00$ value & & 17 May 1999-29 July 2001 & \\
\hline
\end{tabular}

KOBOS trading system (continuous trading at variable prices) was introduced with continuous trading of 7 issues. At the same time the trading hours were expanded till 1:00 pm. Since 16 March 1998 the trading lasts until 3:00 pm. On 25 May 1998 the SPAD (continuous trading) was introduced.

Although the introduction of the KOBOS continuous trading was based on seven stocks only, these were the most traded shares. It is sensible to assume that although most of the shares listed on the exchange would have their price fixed at 11:00 am, the closing value of the PX50 index contained information that would enter the exchange after the fixed-price session closed. Therefore, we assume that the closing values of the PX50 index calculated at 1:00 pm between 15 March 1996 and 24 May 1998 contain information representative for the whole exchange.

This results in the following matching procedure. The time-adjusted S\&P500 index is based on the previous calendar day return until 15 March 1998. Since then the opening values of the S\&P500 are used to match the same day closing values of the PX50. The time-adjusted FTSE100 and DAX30 indices consist of values recorded at 10:00 am until 14 Mach 1996, values recorded at 12:00 pm in the period 15 March 1996-15 March 1998, and at 2:00 pm afterwards.

It is important to note that during the first years, due to a strongly underdeveloped regulatory structure of the PSE and the vast amount of shares listed after the second wave of mass privatisation, only big transactions were recorded.

\subsection{3. $W I G$}

Call trading was also the only way of share exchange on the WSE at the beginning of our sample. Orders that determined prices had to be submitted before 10:00 am for a given trading day. The final values of prices were calculated at 10:15 am, i.e., after "intervention" of a market maker, who modified earlier orders in order to guarantee the highest liquidity of the market. In 1996, in addition to a fixed-price call sessions, continuous trading was introduced. However, it was only the introduction of the WARSET trading system on 16 November 2000 that changed the time at what the final (closing) value of the WIG index was determined. Since then the WIG index has been calculated at $3: 10 \mathrm{pm}$. 
In the light of that, the time-adjusted S\&P500 index consists of lagged closing values until 15 November 2000 and same day opening values since that day. The time-adjusted DAX30 and FTSE100 indices are constructed using 10:00 am values until 15 November 2000 and values recorded at 2:00 pm afterwards.

For the purpose of this analysis the daily exchange rates provided by the corresponding national banks of the emerging markets are used. They are provided before the midday.

\section{Results}

At the end of Section 4 we distinguished 81 different models arising from 9 country pairs, 3 alternative specifications and 3 ways of measuring developed market returns. For obvious reasons we cannot present estimates of all 270 time-paths of the coefficients and 81 time-paths of the variance ratios, but there is no such need, either. This is because several time-paths, although coming from different regression specifications, are indistinguishable. For instance, for each of the emerging markets the time-path of the predictability coefficient, $\gamma_{t}$, is virtually the same whether it comes from Model 2 or 3. Therefore, it is enough to present just one time-path of $\gamma_{t}$ per emerging market. For each emerging-developed country pair the $\beta_{t}$ coefficients obtained for all models (1, 2 and 3 ) look nearly identical within the time-match specification of the developed market return timing, giving in total 28 time-paths. This means that there is hardly any multicollinearity among the regressors. To assess gains from the time matching we discuss in detail time-paths for Hungary with and without time alignment. For the other two countries we present graphs for the time-matched regressions only.

We do not present graphs with time-paths of the $\alpha_{t}$ coefficient as it is never statistically significantly different from zero. Moreover, as $\alpha_{t}$ does not have a clear interpretation, it does not bring anything constructive to our analysis. For the same reason we do not present the estimated time-paths for the exchange rate parameters $\delta_{0 t}$ and $\delta_{1 t}$. None of them was statistically significant at the $5 \%$ level. As the presence of the exchange rates had a negligible impact on the estimates of the time-paths of the other coefficients, we consistently present graphs for Model 2 specification. Although the estimated time-paths of the $\delta_{0 t}$ and $\delta_{1 t}$ parameters are on average indistinguishable from zero, they do improve the fit of the model in terms of the maximum likelihood value. The innovations of these parameters, multiplied by the squared exchange rates, contribute to explaining the conditional heteroskedasticity of the errors in Eq. (1).

Before even starting to discuss time-varying parameter models, we should note that parameters are indeed time-varying. Using the likelihood ratio statistic, the hypothesis of constant parameters $(\Omega=0)$ is rejected overwhelmingly for all models and all data combinations. For the first part of our discussion of the time-varying models we compare all the models using the "static" $R^{2}$ and the Schwartz criterion (SC). The $R^{2}$ s are presented as they are more comparable with time-varying variance ratios that are discussed with the individual country results. However, the SC figures are more informative as a formal model comparison criterion for non-nested ML regressions.

Table 4 reports the $R^{2}$ s of all the model specifications. The $R^{2}$ is defined using the ratio of the residual sum of squares over the total sum of squares. The return alignment dramatically improves the fit of the regressions. For all three emerging markets the time-adjusted regressions give the best fit for all three model specifications and for all three corresponding developed markets. Comparison with the previous day and same day regressions is interesting as well. The previous day returns of the UK and the German indices provide very little explanation as compared with the same day returns. In contrast, a better fit is obtained when the previous day returns are used for 
Table 4

$R^{2}$

\begin{tabular}{|c|c|c|c|c|c|c|c|c|c|}
\hline \multirow{2}{*}{$\begin{array}{l}\text { Model } \\
\text { specification }\end{array}$} & \multicolumn{3}{|l|}{ BUX } & \multicolumn{3}{|l|}{ PX50 } & \multicolumn{3}{|l|}{ WIG } \\
\hline & $\begin{array}{l}\text { Previous } \\
\text { day }\end{array}$ & $\begin{array}{l}\text { Same } \\
\text { day }\end{array}$ & $\begin{array}{l}\text { Time } \\
\text { adjusted }\end{array}$ & $\begin{array}{l}\text { Previous } \\
\text { day }\end{array}$ & $\begin{array}{l}\text { Same } \\
\text { day }\end{array}$ & $\begin{array}{l}\text { Time } \\
\text { adjusted }\end{array}$ & $\begin{array}{l}\text { Previous } \\
\text { day }\end{array}$ & $\begin{array}{l}\text { Same } \\
\text { day }\end{array}$ & $\begin{array}{l}\text { Time } \\
\text { adjusted }\end{array}$ \\
\hline \multicolumn{10}{|l|}{$D A X 30$} \\
\hline Model 1 & 1.5 & 26.4 & 36.5 & 4.4 & 21.8 & 28.8 & 3.8 & 8.5 & 17.3 \\
\hline Model 2 & 3.9 & 26.2 & 36.6 & 8.6 & 23.8 & 31.3 & 6.2 & 11.9 & 21.9 \\
\hline Model 3 & 4.6 & 27.5 & 37.4 & 7.6 & 24.2 & 31.7 & 9.9 & 19.4 & 22.3 \\
\hline \multicolumn{10}{|l|}{ FTSE100 } \\
\hline Model 1 & 4.4 & 20.4 & 34.5 & 6.4 & 20.9 & 24.3 & 4.6 & 7.4 & 16.1 \\
\hline Model 2 & 3.6 & 19.1 & 34.5 & 8.6 & 24.1 & 28.3 & 6.8 & 13.1 & 19.8 \\
\hline Model 3 & 3.8 & 18.4 & 34.5 & 11.6 & 25.5 & 29.2 & 13.5 & 19.1 & 21.0 \\
\hline \multicolumn{10}{|l|}{$S \& P 500$} \\
\hline Model 1 & 12.9 & 6.8 & 22.0 & 7.9 & 8.3 & 11.2 & 13.9 & 1.9 & 15.2 \\
\hline Model 2 & 17.1 & 4.1 & 22.4 & 11.0 & 10.8 & 14.2 & 16.8 & 5.1 & 18.2 \\
\hline Model 3 & 14.6 & 5.4 & 18.1 & 16.0 & 15.7 & 18.9 & 17.2 & 17.3 & 19.5 \\
\hline
\end{tabular}

The table reports $R^{2}$ statistics (\%) for three different specifications of market integration with respect to three different developed markets, three different emerging markets and three measures of aligning daily returns. The $R^{2}$ is defined as one minus the total residual sum of squared residuals divided by the total sum of squared returns.

the US. This is consistent with our earlier discussion on the size of time-mismatch among the markets.

Although the fit of the models seems lowest for the US market regressions, it would be incorrect to conclude that the emerging markets display the lowest level of integration with the US market. The weak result for the S\&P500 index may be driven, at least partially, by the poor matching we achieve using the data in hand. At the same time, it is important to stress that once the timing correction is introduced the explanatory power of regressions using the UK and the German indices is alike.

The joint explanatory power of the previous day return plus the same day return is mostly well below the explanatory power of a regression with the time-adjusted returns. The $R^{2}$ of a regression with both previous day plus same day return as separate independent variables will generally be less than the sum of the separate $R^{2} \mathrm{~s}$. In Table 4 we see that, with a few exceptions, the sum of the $R^{2}$ in the first two columns is still below the $R^{2}$ of the time-adjusted returns. A careful alignment of the data is more effective than a model based solution.

Since the $R^{2}$ statistics may not be meaningful for our ML regressions, Table 5 presents the Schwartz statistics in the form similar to Table 4. Conclusions are the same: the time matching provides a sizable improvement in fit. For each country pair and for each model specification, the time-adjusted regressions have SC values higher than the same day and the previous day regressions. In terms of likelihood values the differences between columns (different time matching) are huge. Differences between rows (different model specification) are less pronounced. In six out of nine model specifications the SC values obtained for the time-adjusted Model 1 are higher than the SC values obtained for same day Model 3. Time matching has more effect on the regression fit than controlling for autocorrelation and exchange rate risk.

The further discussion will be performed country by country. For each emerging market we show (i) how the efficiency measured by the autocorrelation coefficient evolves over time, and (ii) how the time-paths of the impact coefficients and the variance ratios evolve over time. As the 
Table 5

Schwarz criterion (daily observations)

\begin{tabular}{|c|c|c|c|c|c|c|c|c|c|}
\hline \multirow{2}{*}{$\begin{array}{l}\text { Model } \\
\text { specification }\end{array}$} & \multicolumn{3}{|l|}{ BUX } & \multicolumn{3}{|l|}{ PX50 } & \multicolumn{3}{|l|}{ WIG } \\
\hline & $\begin{array}{l}\text { Previous } \\
\text { day }\end{array}$ & $\begin{array}{l}\text { Same } \\
\text { day }\end{array}$ & $\begin{array}{l}\text { Time } \\
\text { adjusted }\end{array}$ & $\begin{array}{l}\text { Previous } \\
\text { day }\end{array}$ & $\begin{array}{l}\text { Same } \\
\text { day }\end{array}$ & $\begin{array}{l}\text { Time } \\
\text { adjusted }\end{array}$ & $\begin{array}{l}\text { Previous } \\
\text { day }\end{array}$ & $\begin{array}{l}\text { Same } \\
\text { day }\end{array}$ & $\begin{array}{l}\text { Time } \\
\text { adjusted }\end{array}$ \\
\hline \multicolumn{10}{|l|}{$D A X 30$} \\
\hline Model 1 & 25,487 & 26,915 & 27,641 & 25,632 & 26,534 & 27,485 & 26,087 & 25,758 & 26,630 \\
\hline Model 2 & 25,598 & 26,898 & 27,642 & 25,585 & 26,443 & 27,469 & 26,327 & 25,611 & 26,648 \\
\hline Model 3 & 25,627 & 26,971 & 27,696 & 25,586 & 26,392 & 27,476 & 26,171 & 25,664 & 26,373 \\
\hline \multicolumn{10}{|l|}{ FTSE100 } \\
\hline Model 1 & 24,672 & 24,916 & 25,411 & 24,715 & 24,857 & 25,340 & 24,715 & 24,857 & 25,340 \\
\hline Model 2 & 24,789 & 25,091 & 25,666 & 24,822 & 25,160 & 25,551 & 25,373 & 24,733 & 25,453 \\
\hline Model 3 & 25,210 & 25,390 & 25,873 & 25,411 & 25,373 & 25,791 & 25,621 & 25,265 & 25,697 \\
\hline \multicolumn{10}{|l|}{$S \& P 500$} \\
\hline Model 1 & 28,662 & 29,629 & 30,080 & 28,765 & 29,568 & 29,782 & 28,880 & 28,902 & 29,052 \\
\hline Model 2 & 28,874 & 29,744 & 30,243 & 28,870 & 29,760 & 30,031 & 29,036 & 29,021 & 29,215 \\
\hline Model 3 & 28,836 & 29,736 & 30,274 & 29,036 & 29,815 & 30,100 & 29,113 & 29,262 & 29,318 \\
\hline
\end{tabular}

The entries report the Schwartz criterion defined as $\mathrm{SC}=2 \ln L-k \ln T$, where $L$ is the maximum likelihood value, $k$ is the number of free parameters, and $T$ is the number of observations. Bold entries indicate the maximum over nine models for the same country pair.

integration indictors are affected by the choice of the developed market index timing, they will be discussed for different time specifications.

\subsection{Hungary: $B U X$}

Fig. 2 shows the time-path of the predictability coefficient plus a $95 \%$ confidence interval. ${ }^{21}$ It documents that the BUX index became less autocorrelated over time. After the initial period with a relatively stable autocorrelation of about 0.4 , the predictability of the index drops to zero in early 1999 and remains statistically insignificantly different from zero (at a 5\% level) ever since.

The next three graphs, i.e., Figs. 3-5, present time-paths of the impact coefficients of the BUX index with the three developed market indices. Each graph shows three time-paths that are estimated for the three different specifications of the developed market returns. The thickest line denotes estimates obtained for the time-adjusted returns, the thinner line corresponds to the estimates obtained for the same day returns, and the thinnest line for the previous day returns.

As expected, the time-adjusted coefficients show the highest level of responsiveness of the BUX index to the western indices. The same day $\beta_{t}$ coefficients are higher than the previous day $\beta_{t}$ 's for the German and the UK markets. The opposite is true for the US index. However, this should not be surprising, as previous day closing values of the S\&P500 index were used to construct the previous day and the time-adjusted series for the first few years of the investigated period. The higher responsiveness of the BUX index to the time-adjusted S\&P500 index estimated for the last few years can be attributed to the better time-match of the indices.

The size of the impact coefficients changes over time. The largest values are obtained for the middle part of the period with the two highest spikes, visible in 1997 and 1998, corresponding to the Asian and the Russian Crises respectively. Although the impact coefficients decline rapidly in

\footnotetext{
21 The same format will be used for the other two markets.
} 


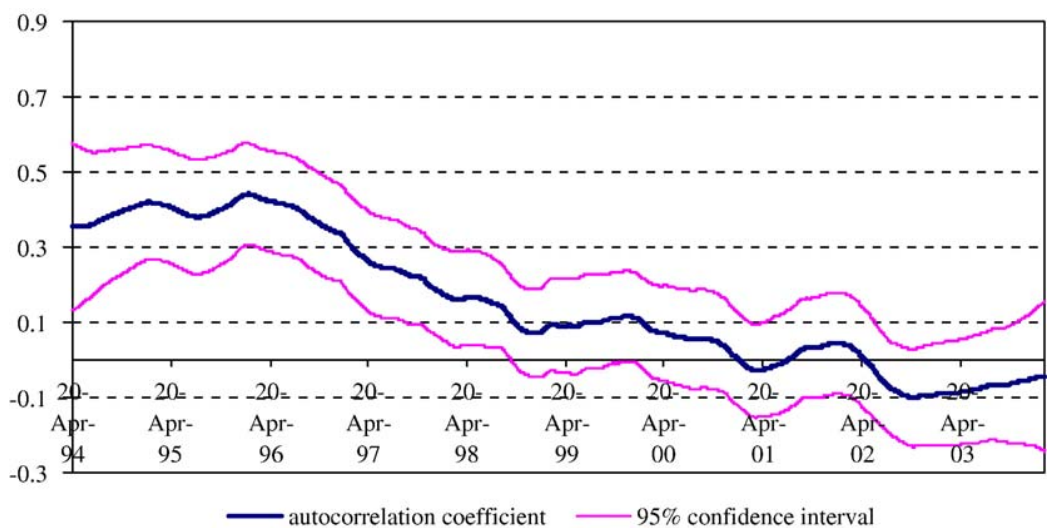

Fig. 2. Time-path of the autocorrelation coefficient estimated for the BUX index.

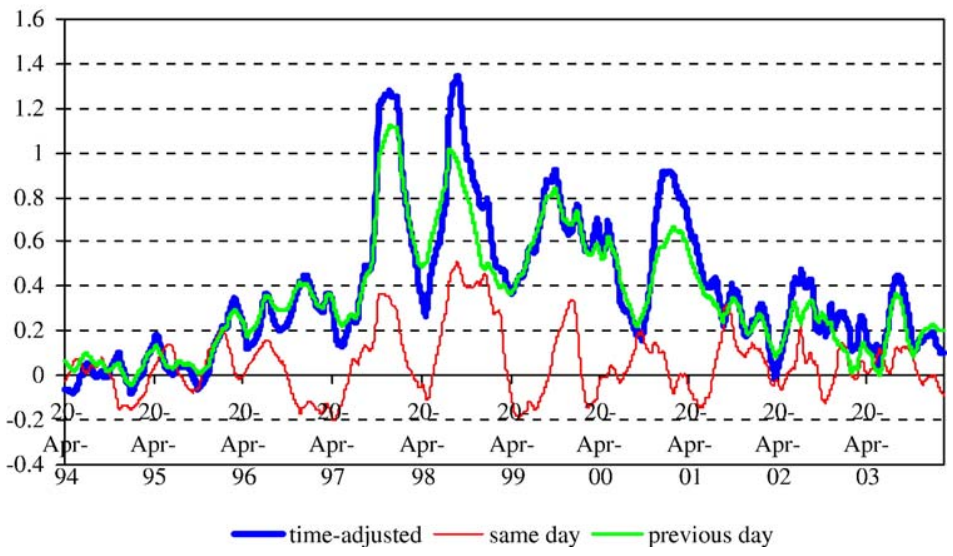

Fig. 3. Evolution of the impact coefficient estimated for the BUX index with the DAX index.

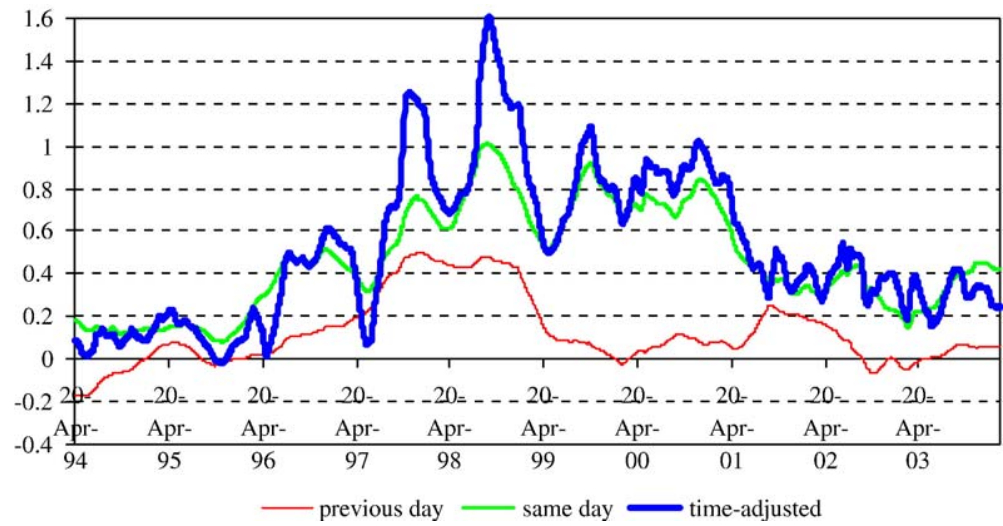

Fig. 4. Evolution of the impact coefficient estimated for the BUX index with the FTSE100 index. 


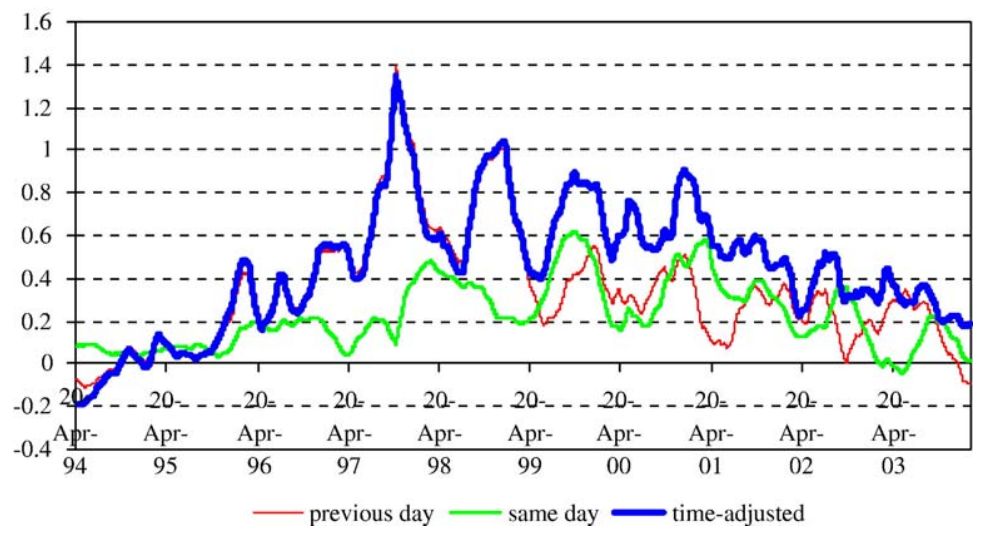

Fig. 5. Evolution of the impact coefficient estimated for the BUX index with the S\&P500 index.

the months following the Russian Crisis the decline is only temporary. Approximately a year after the Russian Crisis (i.e., in late 1999) the impact coefficients rise again and stay at relatively high levels of about $0.6-0.8$ for nearly 2 years, i.e., until mid-2001. Since the increase is not permanent (the 2002-2004 estimates are much lower), and, as we will see in Sections 6.2 and 6.3, it also appears on the other two emerging markets at the same time, we suspect that international rather than national factors are the cause. There was no international (emerging market) crisis that lasted over 2000 and 2001 and that could naturally be linked to the high values of the impact coefficients. However, the 2000-2001 period was dramatic on developed markets across the world. It was the time of the post e-commerce bubble correction during which many developed stock markets experienced large losses. ${ }^{22}$ Although, the Hungarian market, or any other emerging markets of the CEE, did not really experience a high-tech bonanza, it might be negatively affected by the collapse. If international investors experienced losses on their investments on developed markets in 2000-2001, they might have liquidated their holdings on many markets, including the Hungarian one. In consequence, cross-market correlations and the estimated values of the impact coefficients would increase. This line of reasoning is consistent with Boyer et al.'s (2006) argument that it is international investors who spread financial crisis.

The estimates obtained for the most recent period are much lower, although they are still statistically significant for the FTSE100 and the S\&P500 indices for which the most recent values of the estimated impact coefficients are marginally higher than those of the DAX30 index, whereas the size of the standard errors of the estimated impact coefficients is similar across the three developed markets (about 0.17 on average). For the sake of space we present the 95\% confidence intervals for the DAX30 estimates only (Fig. 7), the least favourable graph if the statistical significance of the coefficients is the criterion. ${ }^{23}$

\footnotetext{
${ }^{22}$ Although we use the terminology "e-commerce bubble" financial literature is divided in its assessment of the causes of the rise of prices of high-tech companies, i.e., correct valuation versus bubble (see for example, Ofek and Richardson, 2003; Pastor and Veronesi, in press, 2005; Schultz and Zaman, 2001; Schwert, 2002). Grout and Zalewska (2006) show that significant changes in market risk took place during the "e-commerce bubble".

23 Since the regressions with the DAX30 index as an explanatory variable tend to have the lowest values of the impact coefficient across all emerging markets, we choose them as the base of the statistical significance test. This is because, since standard errors are comparable, marginal significance of the DAX30 impact coefficients will indicate statistical significance of the FTSE100 and the S\&P500 impact coefficients.
} 


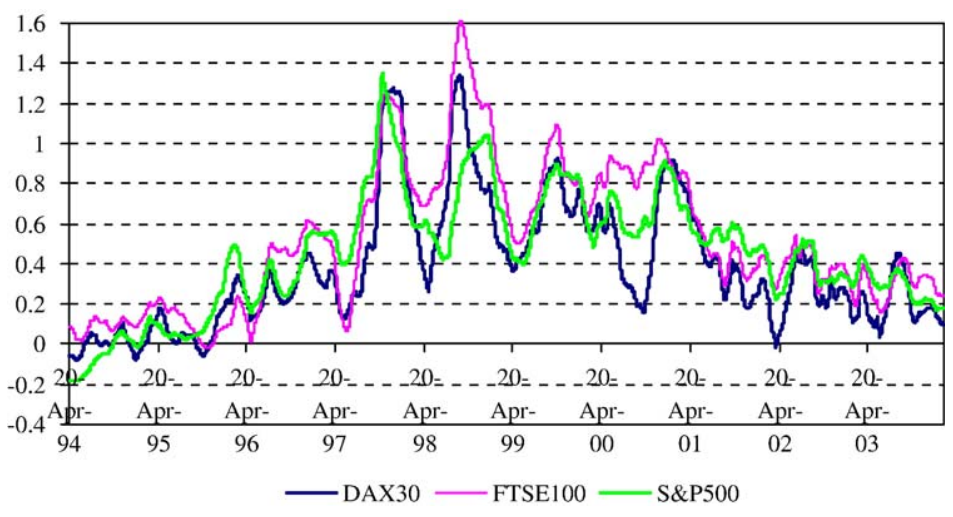

Fig. 6. Comparison of the impact coefficients estimated for the BUX index (time-adjusted regressions).

If the analysis were restricted to the same day returns only, we would easily conclude that the impact coefficients are very low and decline with geographical distance. It is the time-alignment that makes the three time-paths of the impact coefficient look alike both in size and pattern. To highlight this similarity Fig. 6 plots all the time-adjusted impact coefficients together. The spikes of the Asian and Russian Crises are very similar in magnitude and very short-lived. The impact coefficients return to their pre-crises levels within just a few months, and again the "post-crises" estimates obtained for the three western markets are very similar. The same can be said about the levels of the coefficients estimated for the period of the correction after the e-commerce bubble and the most recent years indicating that the BSE's comovement with the European markets and the geographically more distant US market are very much alike.

To complete the analysis we consider the variance ratios as a measure of time-varying correlation. Fig. 8 plots the variance ratios obtained for the regressions based on the time-adjusted returns for the three developed market indices (as Fig. 6 does for the impact coefficients). The variance ratios show a very similar pattern. They are initially very low and increase to $60-80 \%$ in the middle part of the sample, and subsequently decline in the most recent months. The high volatility of the ratios is a consequence of using the $\mathrm{GARCH}$ specification for the variance of the error term.

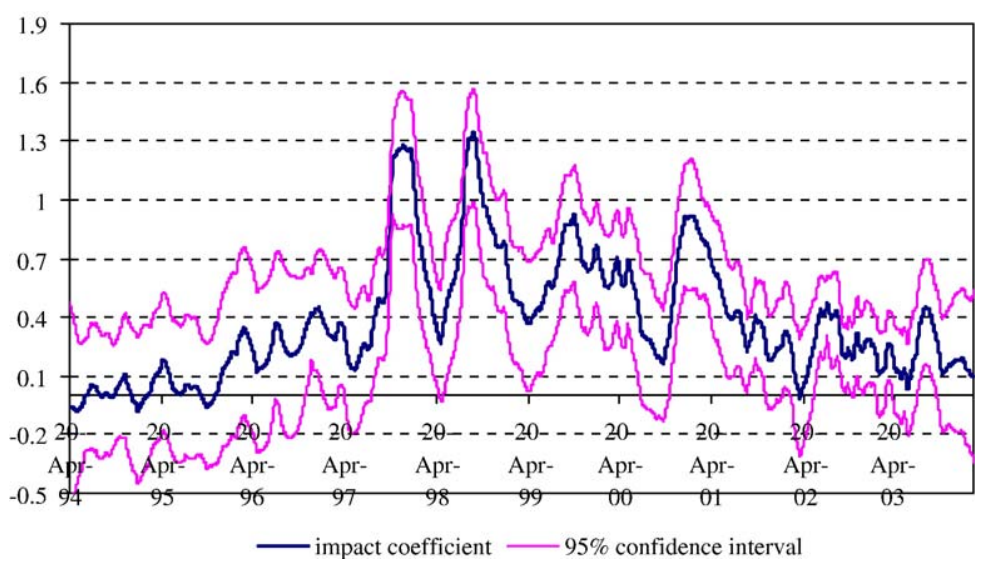

Fig. 7. Time-path of the impact coefficient of the DAX30 index estimated for the BUX index. 


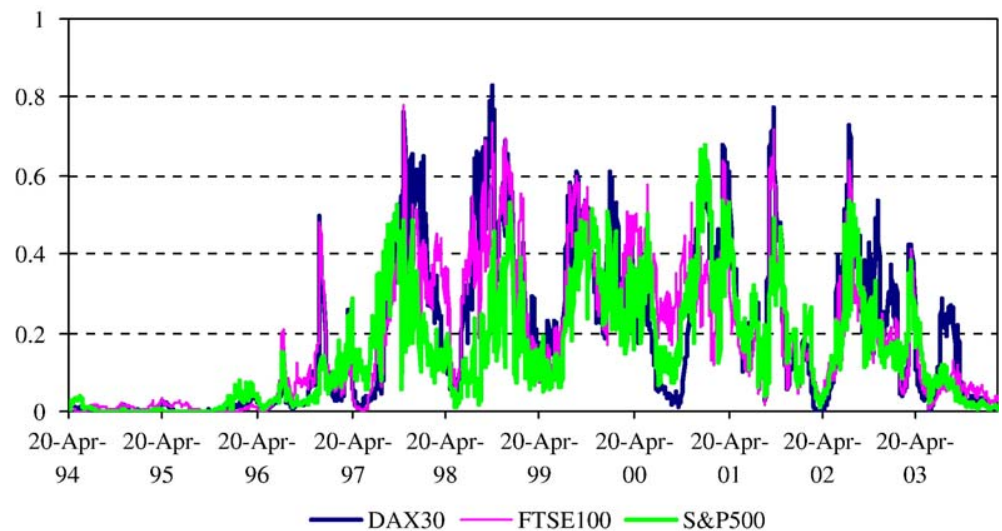

Fig. 8. Comparison of the variance ratios calculated for the BUX index.

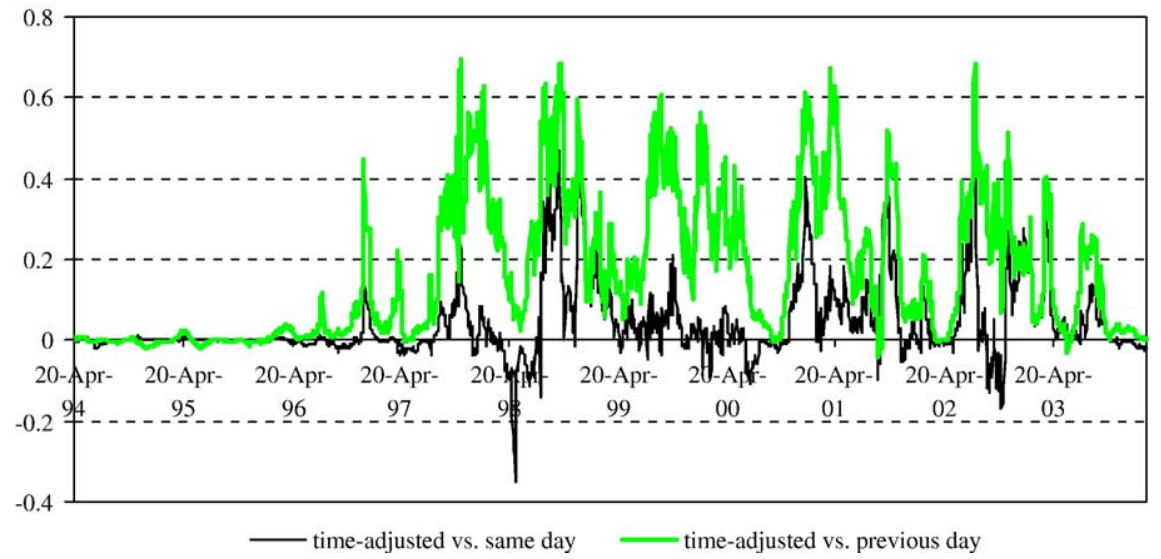

Fig. 9. Comparison of the differences of the variance ratios for the BUX index and the DAX index.

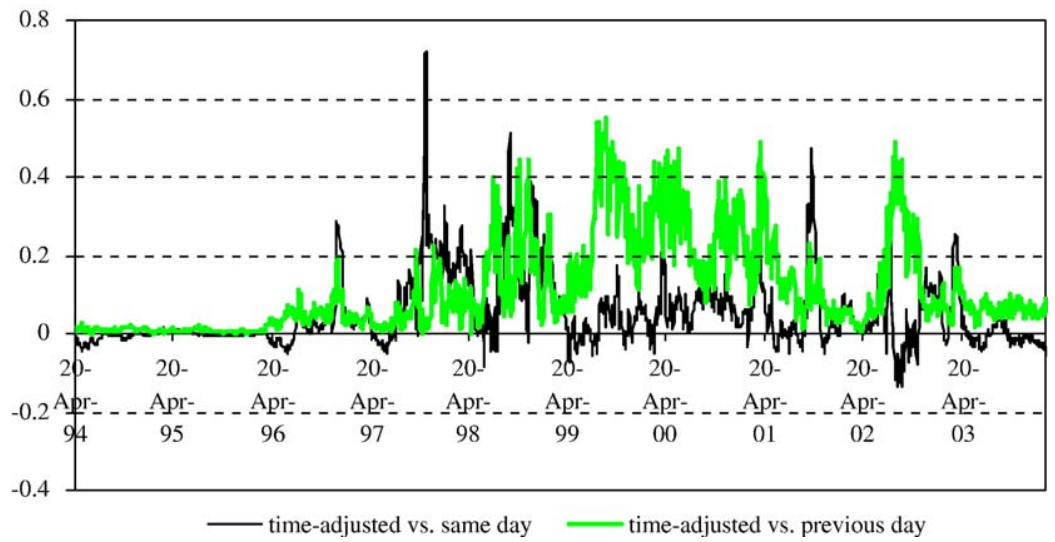

Fig. 10. Comparison of the differences of the variance ratios for the BUX index and the FTSE100 index. 


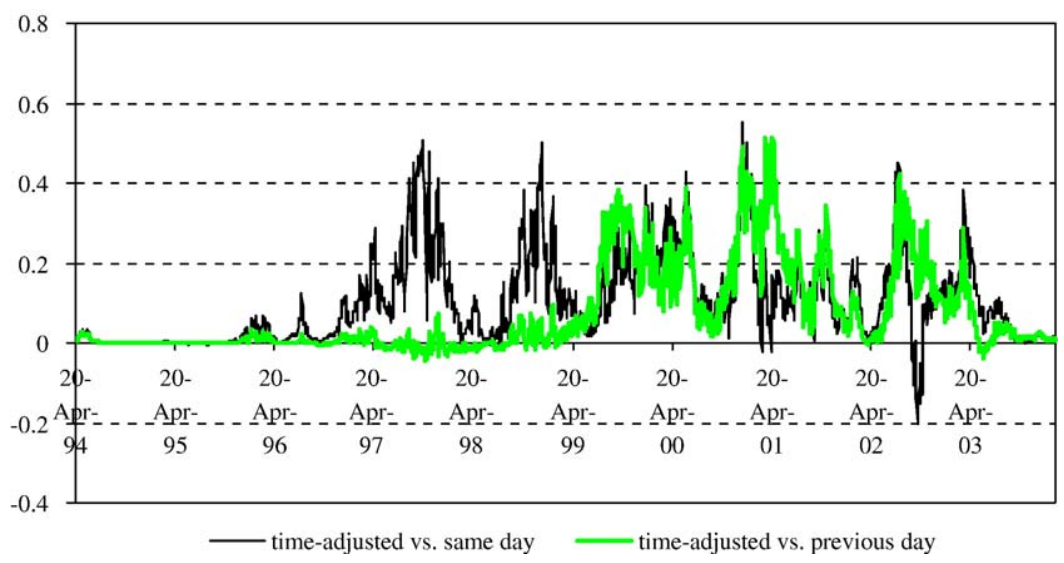

Fig. 11. Comparison of the differences of the variance ratios for the BUX index and the S\&P500 index.

Comparison of the variance ratios for different data adjustments of the developed market returns confirms the findings presented in Tables 4 and 5: the best fit is achieved for the timeadjusted regressions. Figs. 9-11 show two time-paths each. One, a thin line, shows the differences between the variance ratios obtained for the time-adjusted regressions and the variance ratios calculated for the regressions using the same day returns. The other line, the thick one, plots the difference between the variance ratios calculated for the time-adjusted regressions and the variance ratios calculated for the previous day regressions. As expected, the greatest difference is observed for the regressions using the previous day returns for the DAX30 and the FTSE100 indices. This result is somehow reversed for the S\&P500 index. This confirms our earlier discussion and predictions on the consequences of time-zone differences among the markets.

\subsection{Czech Republic: PX50}

Fig. 12 shows that the path of the autocorrelation estimated for the PX50 index looks very smooth. Although the initial values are relatively high, they decline steadily over time. Indeed, the

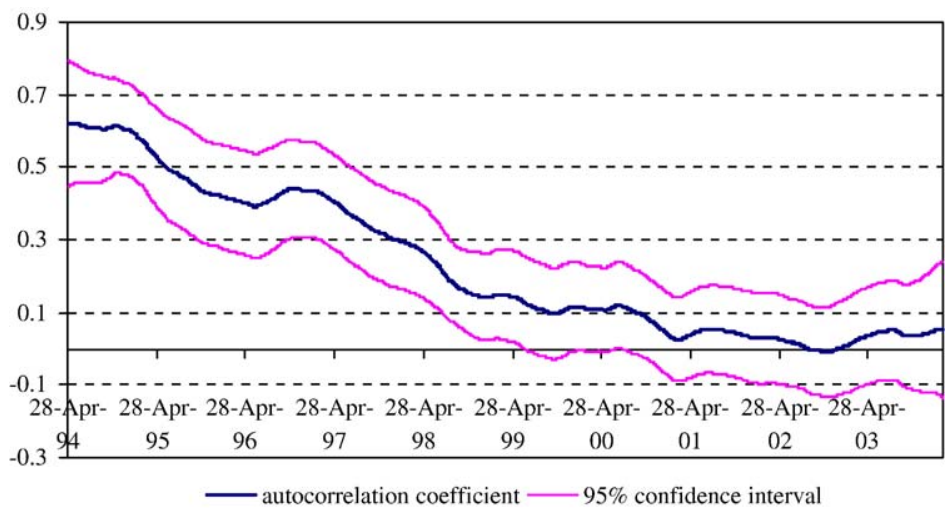

Fig. 12. Time-path of the autocorrelation coefficient estimated for the PX50 index. 


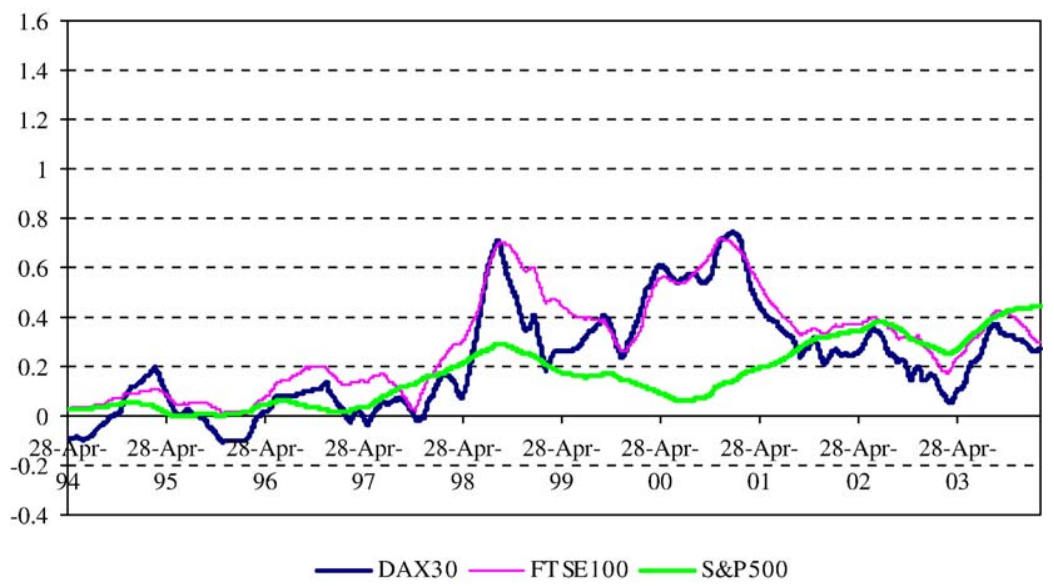

Fig. 13. Comparison of the impact coefficients estimated for the PX50 index (time-adjusted regressions).

initial autocorrelation of the PX50 index is twice as large as the values estimated for the other two emerging markets. The low level of regulation of the market and weak protection of minority shareholders that the PSE offered its new clients during and after the mass privatisation programme may be responsible for the situation. The marginal increase in the coefficient in 1996 coincides in time with the period of economic distress and financial market crisis that brought about a collapse of many banks and the withdrawal of many companies from the exchange. However, since mid-1999 the index does not show any statistically significant autocorrelation.

As in the Hungarian case the time-adjusted regressions deliver the highest impact coefficients and variance ratios. It also remains true that the better match is obtained when the same day rather than the previous day returns are used in the regressions with the DAX30 and the FTSE100 indices. The opposite is true in the case of the S\&P500 index.

Figs. 13 and 15 show the time-paths of the impact coefficients and corresponding variance ratios estimated for the three developed market regressors when the time-adjusted series of returns are used. Until the end of 2001 the highest values of the coefficients are estimated for the German and the UK indices, however, the 2003-2004 estimates are marginally highest for the US index.

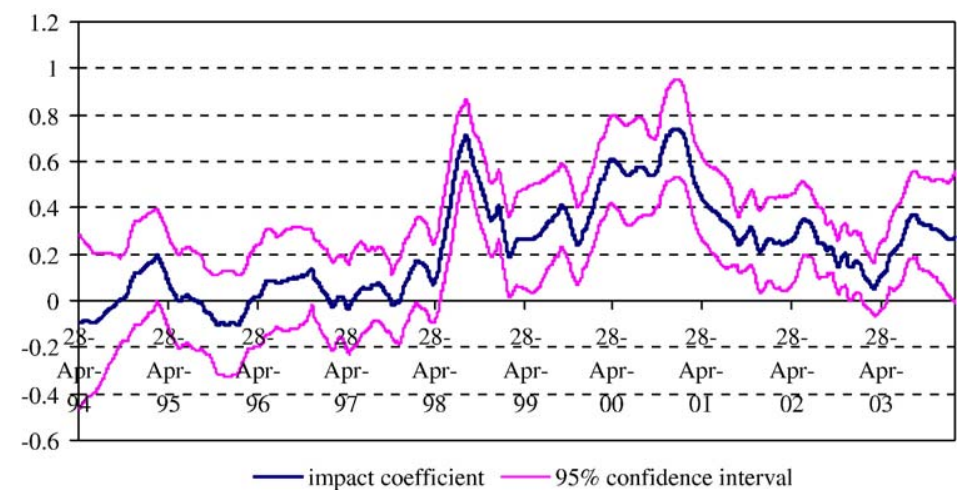

Fig. 14. Time-path of the impact coefficient of the DAX30 index estimated for the PX50 index. 


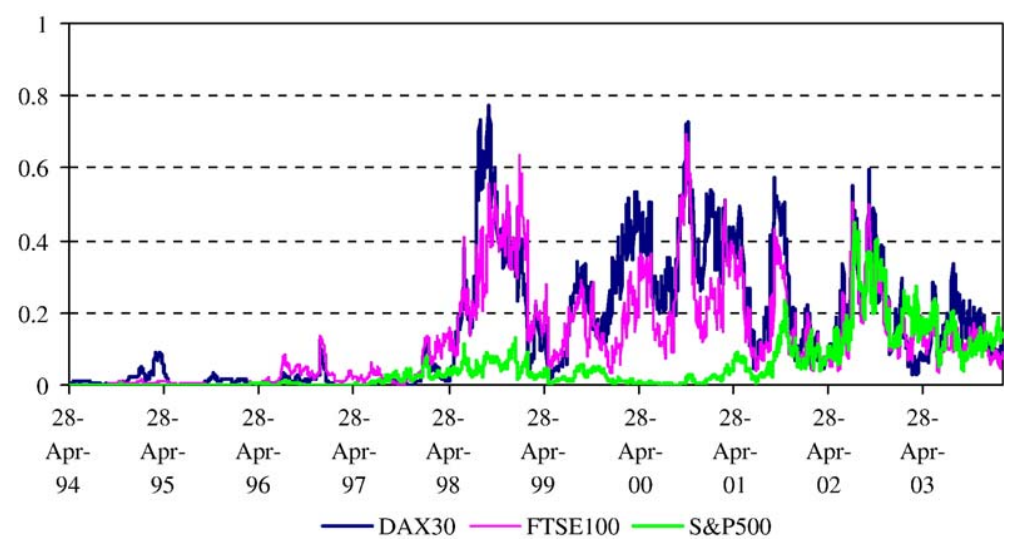

Fig. 15. Comparison of the variance ratios calculated for the PX50 index.

The Czech impact coefficients are lower than the ones estimated for the BUX index in the first half of the sample. In contrast with the Hungarian results, there is only one spike in 1998 and is much lower than those estimated for the Hungarian market. A possible explanation is that in 1997 the Czech economy was still recovering from the crisis of 1996 and major changes in the financial sector were taking place. Whereas the PSE listed 1670 companies at the end of 1996, it had only 320 listings a year later. Since the market was driven by strong internal factors, it did not manifest any sensitivity to the external ones. However, since 1998 the situation on the market has been relatively stable in this sense that the Exchange has not experienced any further massive numbers of delistings and new offerings. Moreover, international investors have entered the market. This may be the explanation why the 2000-2001 impact coefficients estimated for the PSE are similar in magnitude to those obtained for the BSE when the UK and German markets are used as regressors.

For the S\&P500 index the 1998 increase of the impact coefficient is moderate, as it does not rise above 0.25 . Since 2001, however, the values for the US market are as high as for the other two developed market indices. The time-paths of the impact coefficient are statistically different from zero at the $5 \%$ level since $1998 .^{24}$ Fig. 14 shows the time-path of the impact coefficient and its 95\% confidence intervals estimated against the DAX30 index. Again, as in the case of the BUX index, the impact coefficient estimated against the German index is lowest among the developed markets in the 2001-2004 period, which means that the impact coefficients estimated for the other two developed market indices are statistically different from zero at the 5\% level.

The pattern of the impact coefficients is mirrored by the variance ratios (Fig. 15), i.e., the clear distinction between the pre-1998 and after-1998 values can be drawn. The after-2001 variance ratios calculated for the S\&P500 are similar to the ratios calculated for the other two developed market indices.

\subsection{Poland: WIG}

As in the case of the other emerging markets, the WIG index's autocorrelation coefficient has become statistically insignificant from zero by the end of the sample period (see Fig. 16).

\footnotetext{
24 The estimates against the S\&P500 index get statistically insignificantly different from zero for a short period of time around April 2000.
} 


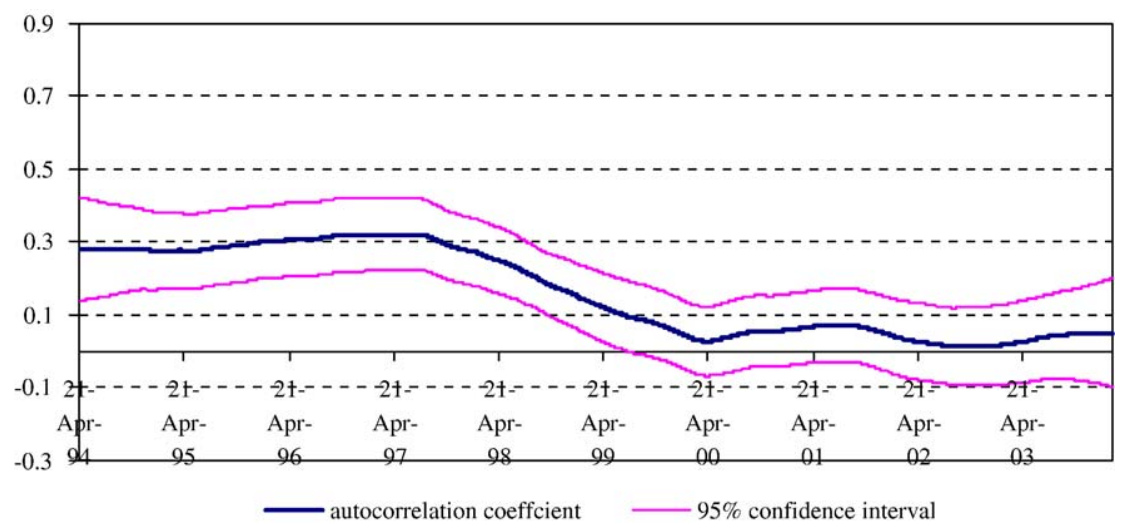

Fig. 16. Time-path of the autocorrelation coefficient estimated for the WIG index.

Although the market seems least autocorrelated (among the three discussed in the paper at the beginning of our sample) it took more time for the autocorrelation to disappear than it did on the other markets. It was only in 2000 that the estimated time-paths became statistically indistinguishable for zero. This result may reflect the fact that, although in July 1996 continuous trading of selected shares took place after the fixed-price session results were announced, the WIG index closing values were based on the fixed-price session results only. The expansion of the market index to continuous trading took place in November 2000.

Fig. 17 shows that the time-paths of the impact coefficients estimated for the time-adjusted time series are very similar across developed market indices, with the impact coefficient estimated against the DAX30 index being persistently lowest. However, the initial values of the three impact coefficients are higher than those estimated for the other two emerging markets, and become statistically different from zero at the 5\% level as early as 1996 for the FTSE100 and S\&P500 estimates and since 1997 for the DAX30 estimates, and remain statistically significant for the rest of the sample (see Fig. 18). At the same time the 1997 and the 1998 crises are much less pronounced than in the case of the BUX index, but the increase in the impact coefficients is clearly visible in 2000. However, in contrast with the

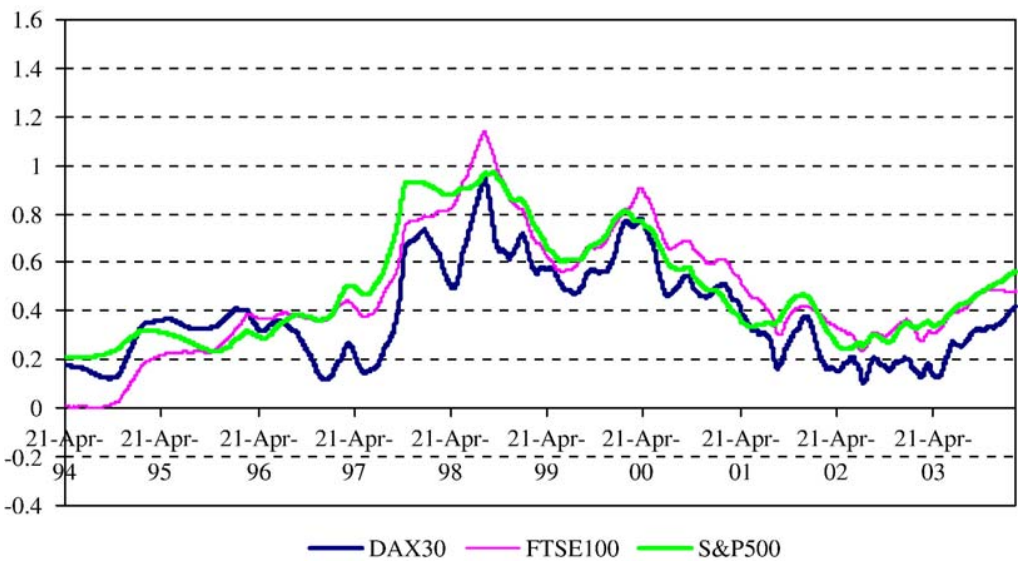

Fig. 17. Comparison of the impact coefficients estimated for the WIG index (time-adjusted regressions). 


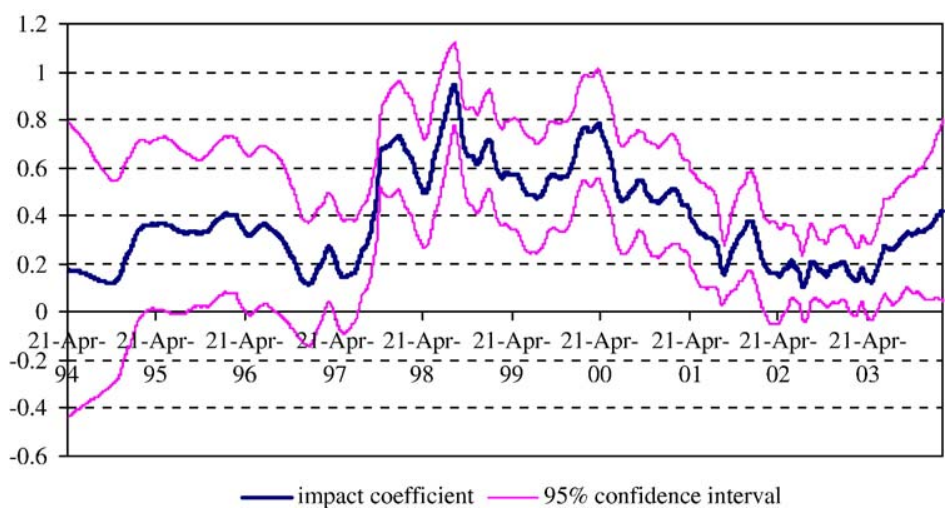

Fig. 18. Time-path of the impact coefficient of the DAX30 index estimated for the WIG index.

other two markets, the WSE 2001 figures are already on a downward slope. This "break in the pattern" may result from internal factors. In 2000 the Polish exchange experienced an emergence of a new group of investors, domestic pension funds, and with them significant cash inflows. Starting from a practically zero level of equity investment at the end of 1999 the Polish pension funds held $\$ 1.3 \mathrm{bn}$ worth of shares (i.e., 5.2\% of the equity market capitalisation) by the end of 2001. A year later the equity investment increased to $\$ 2.24 \mathrm{bn}$ or $7.8 \%$ of the equity market capitalisation. Not surprisingly such a massive cash inflow had a strong impact on the WSE development and market characteristics. Zalewska $(2005,2006)$ reports that in the case of many companies listed on the WSE the local pension funds have taken over $70-80 \%$ of their free float. The ratio of total value traded to market capitalisation in 2002-2003 was less than half of that observed in 1996-1997. In the light of this, it is likely that the Polish market might display smaller sensitivity to the post-e-commerce increase in cross-country corrections than the Hungarian and the Czech markets did.

The variance ratios are similar for all three developed markets' indices. They clearly increase during the Asian and the Russian Crises, but seem to be in decline since then (Fig. 19).

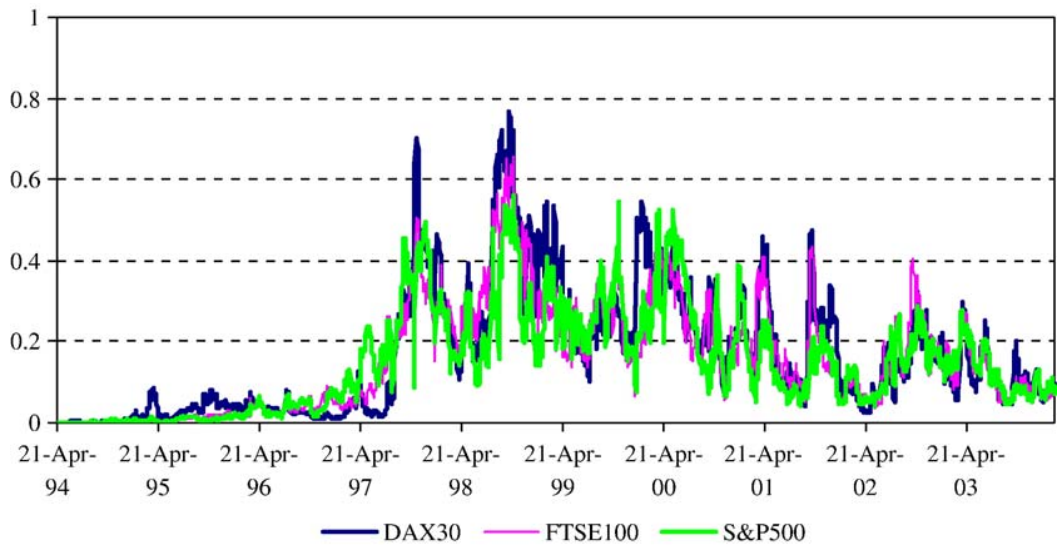

Fig. 19. Comparison of the variance ratios calculated for the WIG index. 
Table 6

Schwarz criterion (weekly observations)

\begin{tabular}{|c|c|c|c|c|c|c|c|c|c|}
\hline \multirow{2}{*}{$\begin{array}{l}\text { Model } \\
\text { specification }\end{array}$} & \multicolumn{3}{|l|}{ BUX } & \multicolumn{3}{|l|}{ PX50 } & \multicolumn{3}{|l|}{ WIG } \\
\hline & Previous day & $\begin{array}{l}\text { Same } \\
\text { day }\end{array}$ & $\begin{array}{l}\text { Time } \\
\text { adjusted }\end{array}$ & $\begin{array}{l}\text { Previous } \\
\text { day }\end{array}$ & $\begin{array}{l}\text { Same } \\
\text { day }\end{array}$ & $\begin{array}{l}\text { Time } \\
\text { adjusted }\end{array}$ & $\begin{array}{l}\text { Previous } \\
\text { day }\end{array}$ & $\begin{array}{l}\text { Same } \\
\text { day }\end{array}$ & $\begin{array}{l}\text { Time } \\
\text { adjusted }\end{array}$ \\
\hline \multicolumn{10}{|l|}{$D A X 30$} \\
\hline Model 1 & 1930.27 & 1974.46 & 2017.53 & 2153.02 & 2198.79 & 2205.74 & 1693.49 & 1714.81 & 1730.13 \\
\hline Model 2 & 1954.48 & 1988.25 & 2025.69 & 2142.37 & 2191.11 & 2195.45 & 1687.00 & 1709.67 & 1724.39 \\
\hline Model 3 & 1895.16 & 1927.37 & 2000.46 & 2183.57 & 2217.89 & 2220.33 & 1746.57 & 1767.51 & 1758.83 \\
\hline \multicolumn{10}{|l|}{ FTSE100 } \\
\hline Model 1 & 1919.40 & 1967.20 & 1980.10 & 2125.38 & 2159.82 & 2166.87 & 1693.49 & 1714.81 & 1730.13 \\
\hline Model 2 & 1916.34 & 1957.60 & 1975.02 & 2096.13 & 2145.70 & 2156.51 & 1686.86 & 1711.38 & 1725.18 \\
\hline Model 3 & 1924.61 & 1981.89 & 1991.22 & 2114.03 & 2158.91 & 2187.49 & 1723.06 & 1743.43 & 1750.72 \\
\hline \multicolumn{10}{|l|}{$S \& P 500$} \\
\hline Model 1 & 1932.56 & 1931.17 & 1943.40 & 2091.51 & 2122.51 & 2102.94 & 1693.49 & 1714.81 & 1730.13 \\
\hline Model 2 & 1930.25 & 1924.89 & 1959.33 & 2070.91 & 2117.61 & 2088.74 & 1733.66 & 1705.24 & 1739.76 \\
\hline Model 3 & 1958.45 & 1957.68 & 1965.05 & 2108.06 & 2176.20 & 2115.43 & 1749.90 & 1730.82 & 1743.78 \\
\hline
\end{tabular}

The entries report the Schwartz criterion defined as $\mathrm{SC}=2 \ln L-k \ln T$, where $L$ is the maximum likelihood value, $k$ is the number of free parameters, and $T$ is the number of observations. Bold entries indicate the maximum over nine models for the same country pair.

\subsection{Weekly data}

A natural question at this point is whether increasing data frequency is really worthwhile, and whether similar results could not have been obtained at a lower cost, i.e., using a lower data frequency (e.g., weekly) for which the problem of time mismatch should not be that significant, if at all. Table 6 shows the SC values equivalent to those presented in Table 5, but this time obtained for the weekly frequency data. ${ }^{25}$ For 22 out of 27 specifications the Schwartz criterion still favours the model with time-adjusted returns.

Apart from providing a better fit, using the time-matched weekly returns also results in different estimates of the time-paths of the impact coefficient when compared with the sameday and previous-day returns. As an example we show the impact coefficient estimated for Hungary with Germany as the developed market comparator. Fig. 20 shows the differences in the estimated time-paths of the impact coefficient. It is apparent that the time-adjusted series is the only one that clearly distinguishes between the Asian Crisis of 1997 and the Russian Crisis of 1998, although the Asian Crisis is less pronounced. The same-day time series (which would probably be the most commonly used if weekly frequency were chosen) would not pick the crises as separate events. The increase in the estimated values of the time-path is relatively smooth until the peak of 1998. We can expect that when the frequency is lowered to monthly observations the time-path of 1997-1998 period blurs in a smoother pattern still. Indeed, using monthly data Pajuste et al. (2000) and Mateus (2004) can only detect a general change in their estimates around 1998.

\footnotetext{
25 The weekly data are constructed on a Tuesday-to-Tuesday basis. The choice of the days was dictated by the opening days of the Polish and the Czech exchanges that at the beginning of our sample traded only a few times a week. Weekly time-matched data are calculated as weekly returns using intra-trade values of the developed market indices as specified in Table 3.
} 


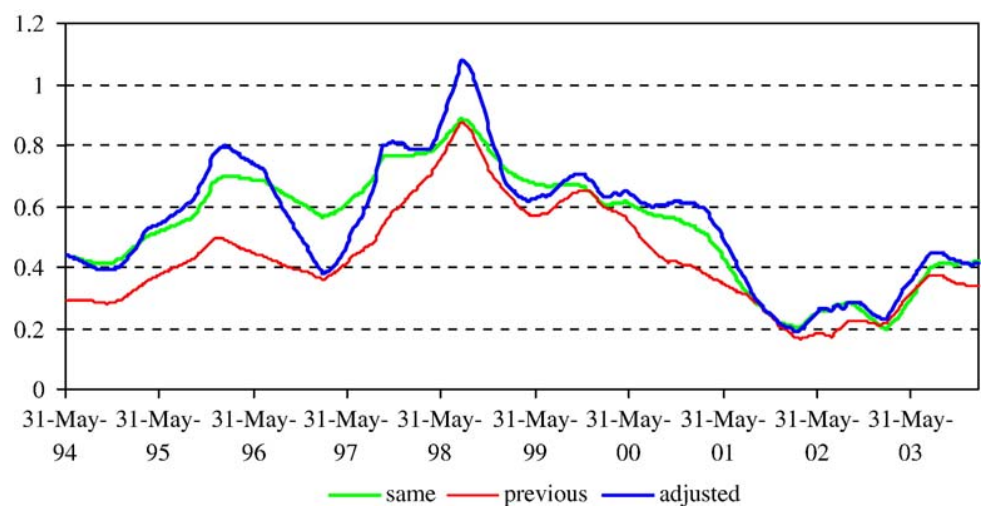

Fig. 20. Evolution of the impact coefficient estimated for the BUX index with the DAX index (weekly observations).

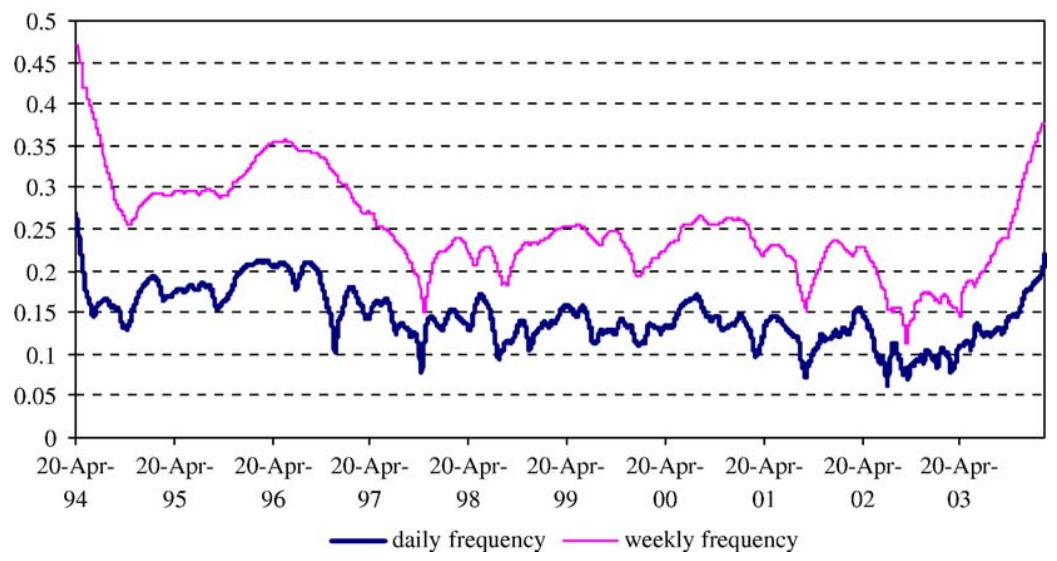

Fig. 21. Comparison of the standard errors estimated for the impact coefficient for the BUX index with the DAX index using data of daily and weekly frequency.

Higher standard errors of the estimated coefficients are an additional side effect of using lower frequency data. Fig. 21 plots standard errors estimated for the impact coefficient for the BUX index with the DAX index for the daily and weekly time series. The standard errors estimated for the weekly data are around 0.25 and only rarely drop below 0.20 even around the crisis periods. Given the scale of the changes in the impact coefficient, daily data are the only means of documenting significant temporary changes.

\section{Conclusions}

A time-mismatch arises when stock market returns used in regressions are recorded on different exchanges at different times. For daily returns recorded on three emerging markets of Central and Eastern Europe and three developed markets (UK, US and Germany) we show that time-mismatch requires careful handling to avoid misinterpretation of the evidence. Moreover, time alignment leads to far higher $R^{2}$ and higher impact coefficients, $\beta_{t}$, than same-day and previous-day returns. Corrections for time-mismatch remain important for these markets even when using weekly returns. 
When assessing our measures of market integration (i.e., impact coefficients and variance ratios) three periods emerged: (i) the initial period of low values between 1994 and 1996, (ii) the middle period of higher values between 1997 and 2000, and (iii) the 2001-2004 period with values similarly low to those estimated in the initial period. By far the largest values of the coefficients and variance ratios occur during the Asian and the Russian Crises. The most pronounced effect is observed on the Hungarian market. This may be because our time-match was best for the BSE. However, another explanation, following Boyer et al. (2006), could be that the BSE was most open to foreign capital and participation among the three emerging markets that we discuss in this paper. Therefore, the exposure to external shocks could be stronger on the BSE than on the other two markets. This argument is consistent with the fact that the impact of the Asian Crisis of 1997 is not observable on the Czech exchange, whereas, in general, 1997 was very dramatic for the PSE and the Czech economy. However, the economic and financial breakdown in the Czech economy was of domestic origin. Rapid mass privatisation was not supported by thorough banking sector reforms or by corporate governance restructuring of the banks and privatised enterprises. This resulted in a currency crisis, slowdown of economic growth and a massive bailout of banks. Consequently, 1301 illiquid companies had to be withdrawn from the Free Market of the PSE in 1997 alone. However, since the situation on the market has stabilised, and restrictions of foreign investment have been relaxed the PX50 index displays a similar pattern of the impact coefficient to those observed for the BUX and the WIG indices.

It is interesting to note that although the impact coefficients declined substantially after the shock of the Russian Crisis declined, they were still considerably higher than those estimated for the most recent period. Although testing for factors that determine changes in the impact coefficient is outside the scope of this paper, we hypothesize that the relatively high values of the impact coefficient could be the result of a correction that shook world markets after the ecommerce bubble has burst. Though the end of the e-commerce euphoria cannot be classified as a crisis (it had no macroeconomic origins and implications), it was the period of high market volatility. The CEE markets have not experienced the high-tech boom because they consist predominantly of "old-economy" stocks. However, this would not protect them from being negatively affected by the "collapse" of the boom. Following from the argument of Boyer et al. (2006), if international investors facing losses on developed markets liquidated their holdings on foreign (emerging) markets, it would result in a "contagion" effect, i.e., an increase in crossmarket correlations. It could explain why our measures of integration remained relatively high until early 2001.

Obviously, international phenomena cannot be the only ones that explain changes in the impact coefficient. Domestic factors may also play a significant role. In this respect it is worth mentioning that the decline in the impact coefficient observed for the WSE (the most current values of the coefficient are lower than those estimated at the beginning of the sample) coincides with the decline in the market liquidity caused by overgrown domestic pension fund investments.

In general, we can conclude that the impact coefficients display strong fluctuations and their recent values are relatively low. These low values may be typical for emerging markets with low liquidity, such as the ones considered in this paper, but, to fully understand the phenomenon, more research on a bigger group of emerging markets is needed. ${ }^{26}$ Definitely, our time-matched

\footnotetext{
26 The coefficient and variance ratios obtained for analogous regressions when returns on the developed market are used as a dependent variable are much higher (about 0.6-0.8). We do not report them to save space, but the results can be obtained from the corresponding author on request.
} 
approach shows a higher level of the integration of the CEE markets with developed markets than studies based on monthly observations (Pajuste et al., 2000; Mateus, 2004) and on nonsynchronised daily observations (Rockinger and Urga, 2001). In addition, our paper shows that during the Asian Crisis correlations with developed markets increased substantially, as did the impact coefficients, $\beta_{t}$. The same dramatic change was observed during the Russian Crisis and, to a smaller extent, during the post e-commerce market correction period. In summary, the CEE markets have been very sensitive to external shocks.

We also confirm that predictability of the CEE markets has decreased over time. The estimated time-paths of the autocorrelation coefficient start at values significantly different from zero, and gradually become indistinguishable from zero as time progresses. It is interesting to note that the initial values of the PX50's autocorrelation coefficient are about twice those estimated for the other market indices. This may be because transparency, and the organisation, in general, of the PSE was far from perfect in the early years of the market's life. The initial introduction of a large number of stocks on the market, that was not physically prepared to operate on such a scale, may be responsible for the initial high level of predictability. This is consistent with the discussion in Glaeser et al. (2001). The PSE was only 1 year old when our sample starts. At that time the other two exchanges had already been operating for 3 to 4 years. Therefore, the lower level of autocorrelation estimated for the BUX and the WIG indices may reflect the higher level of development of these markets by the mid-1990s.

\section{Acknowledgements}

We would like to thank the Editor, Franz Palm, and Paul Grout, Rohan Williamson, and two anonymous referees for useful comments and encouragement during the preparation of this paper.

\section{References}

Adler, M., Dumas, B., 1983. International portfolio choice and the corporation finance: a synthesis. Journal of Finance 38 (3), 925-984.

Aitt-Sahalia, Y., Mykland, P.A., Zhang, L., 2005. How often to sample a continuous time process in the presence of market microstructure noise. Review of Financial Studies 18, 341-351.

Andersen, T.G., Bollerslev, T., Diebold, F.X., Ebens, H., 2001. The distribution of realized stock return volatility. Journal of Financial Economics 61, 43-76.

Andersen, T.G., Bollerslev, T., Diebold, F.X., Labys, P., 2003. Modeling and forecasting realized volatility. Econometrica $71,579-625$.

Bekaert, G., Harvey, C.L., 1995. Time-varying world market integration. Journal of Finance 50 (2), $403-444$.

Bekaert, G., Harvey, C.L., 1997. Emerging market volatility. Journal of Financial Economics 43, $29-77$.

Bekaert, G., Harvey, C.L., 2002. Research in emerging markets finance: looking to the future. Emerging Markets Review 3, 429-448.

Bekaert, G., Harvey, C.L., 2003. Emerging markets finance. Journal of Empirical Finance 10, 3-55.

Bekaert, G., Harvey, C.L., Ng, A., 2005. Market integration and contagion. Journal of Business 78 (1), 39-69.

Boyer, B.H., Kumagai, T., Yuan, K., 2006. How do crises spread? Evidence from accessible in inaccessible stock indices. Journal of Finance 61 (2), 957-1003.

Braker, K., Scott-Docking, D., Koch, P.D., 1999. Economic determinants of evolution in international stock market integration. Journal of Empirical Finance 6, 1-27.

Forbes, K.J., Rigobon, R., 2002. No contagion, only interdependence; measuring stock market comovements. Journal of Finance 57 (5), 2223-2262.

Glaeser, E., Johnson, S., Shleifer, A., 2001. Coase v. the Coasians. Quarterly Journal of Economics 116 (3), $853-899$.

Grout, P.A., Zalewska, A., 2005. On the undervaluation of the privatised enterprises. Economics Letters 86 (2), $215-220$.

Grout, P.A., Zalewska, A., 2006. The impact of regulation on market risk. Journal of Financial Economics 80 (1), 149-184. 
Grout, P.A., Jenkins, A., Zalewska, A., 2004. Privatisation of utilities and the asset value problem. European Economic Review 48 (4), 927-941.

Hamao, Y., Masulis, R.W., Ng, V., 1990. Correlations in price changes and across international stock markets. Review of Financial Studies 3 (2), 281-307.

Martens, M., Poon, S.-H., 2001. Returns synchronization and daily correlation dynamics between international stock markets. Journal of Banking and Finance 25, 1805-1827.

Mateus, T., 2004. The risk and predictability of equity returns of the EU accession countries. Emerging Markets Review 5 , $241-266$.

Ofek, E., Richardson, M., 2003. DotCom mania. The rise and fall of internet stock prices. Journal of Finance 58, $1113-1137$.

Pajuste, A., Kepitis, G., Högfeldt, P., 2000. Risk factors and predictability of stock returns in Central and Eastern Europe. Emerging Markets Quarterly 7-24 (Summer).

Pastor, L., Veronesi, P., 2005. Rational IPO waves. Journal of Finance 60, 1713-1757.

Pastor, L., Veronesi, P., in press. Was there a Nasdaq bubble in the late 1990s? University of Chicago Working Paper 2004. Journal of Financial Economics.

Pretorius, E., 2002. Economic determinants of emerging stock market interdependence. Emerging Markets Review 3 , 84-105.

Rockinger, M., Urga, G., 2001. A time-varying parameter model to test for predictability and integration in the stock market of transition economies. Journal of Business and Economic Statistics 19 (1), 73-84.

Scholes, M., Williams, J., 1977. Estimating betas from nonsynchronous data. Journal of Financial Economics 5, 309-328.

Schultz, P., Zaman, M., 2001. Do the individuals closest to internet firms believe they are overvalued? Journal of Financial Economics 59, 347-381.

Schwert, G.W., 2002. Stock volatility in the new millennium: how wacky is Nasdaq? Journal of Monetary Economics 49 , 3-26.

Serra, A.P., 2000. Country and industry factors in returns: evidence from emerging markets' stocks. Emerging Markets Review 1, 127-151.

Zalewska, A., 2005. Is Locking Domestic Funds into the Local Market Beneficial? Evidence from the Polish Pension Reforms. University of Maastricht. LIFE WP05-004.

Zalewska, A., 2006. Home bias and stock market development. In: Mickiewicz, T. (Ed.), Corporate Governance and Finance in Poland and Russia. Palgrave Macmillan, Houndmills, pp. 271-301.

Zalewska-Mitura, A., Hall, S.G., 1999. Examining the first stages of market performance. A test for evolving market efficiency. Economics Letters 64 (1), 1-12.

Zalewska-Mitura, A., Hall, S.G., 2000. Do market participants learn? The case of the Budapest stock exchange. Economics of Planning 33, 3-18. 